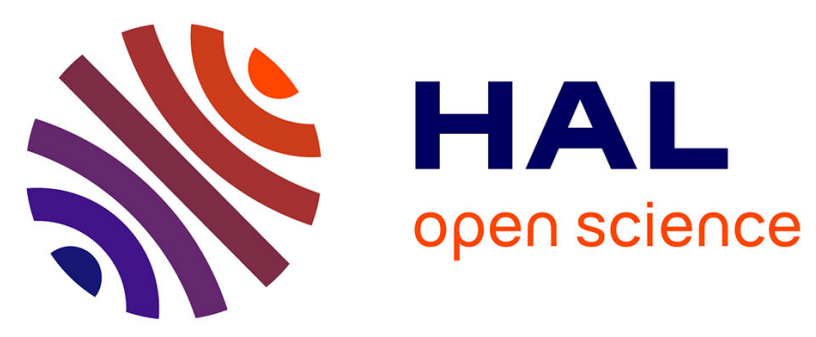

\title{
Evaluation of a variety of a-C:H coatings on PEEK for biomedical implants
}

\author{
Johnny Dufils, Frédéric Faverjon, Christophe Héau, Christophe Donnet, \\ Stéphane Benayoun, Stéphane Valette
}

\section{To cite this version:}

Johnny Dufils, Frédéric Faverjon, Christophe Héau, Christophe Donnet, Stéphane Benayoun, et al.. Evaluation of a variety of a-C:H coatings on PEEK for biomedical implants. Surface and Coatings Technology, 2017, 313, pp.96-106. 10.1016/j.surfcoat.2017.01.032 . hal-01444327

\section{HAL Id: hal-01444327 \\ https://hal.science/hal-01444327}

Submitted on 3 Jun 2020

HAL is a multi-disciplinary open access archive for the deposit and dissemination of scientific research documents, whether they are published or not. The documents may come from teaching and research institutions in France or abroad, or from public or private research centers.
L'archive ouverte pluridisciplinaire HAL, est destinée au dépôt et à la diffusion de documents scientifiques de niveau recherche, publiés ou non, émanant des établissements d'enseignement et de recherche français ou étrangers, des laboratoires publics ou privés. 
Evaluation of a Variety of a-C:H Coatings on PEEK for Biomedical Implants

Johnny DUFILS ${ }^{*}$, Frédéric FAVERJON² ${ }^{2}$ Christophe HEAU ${ }^{2}$, Christophe DONNET ${ }^{3}$, Stéphane BENAYOUN', Stéphane VALETTE ${ }^{1}$

${ }^{1}$ Univ Lyon, Ecole Centrale de Lyon, Laboratoire de Tribologie et Dynamique des Systèmes, UMR 5513, 36 avenue Guy de Collongue, 69134, Écully, France

2 IREIS, HEF group, ZI Sud - Rue Benoît Fourneyron, 42162 Andrézieux-Bouthéon, France

${ }^{3}$ Univ Lyon, Université Jean Monnet, Laboratoire Hubert Curien, UMR 5516, 18 rue Professeur Benoît Lauras, 42000 Saint-Etienne, France

* Corresponding author: Tel.: +33 472186433; Email address: johnny.dufils@doctorant.eclyon.fr (J. Dufils)

\begin{abstract}
Four different hydrogenated amorphous carbon (a-C:H) coatings were deposited on polyether-ether-ketone (PEEK). Their properties in terms of surface roughness, wettability, nanoindentation, residual internal stress, adhesion, scratch resistance, friction and wear resistance were assessed.
\end{abstract}

The two polymer-like carbon coatings were obtained without applying any bias voltage to the substrate. They exhibited very low hardness, Young's modulus and residual internal stress compared with what is generally achieved for diamond-like carbon films. Nonetheless, they enabled to significantly reduce wear when rubbed against an alumina ball. They also showed 
a very good adhesion to the PEEK substrate and a reduction of the coefficient of friction compared with that of the PEEK substrate.

When the titanium layer deposited on the PEEK substrate was biased at either $-50 \mathrm{~V}$ or $-100 \mathrm{~V}$ during the deposition of the a-C:H coatings, the a-C:H coatings were harder, stiffer and more internally stressed than the two polymer-like carbon coatings. However, the a-C:H films obtained with bias voltages of $-50 \mathrm{~V}$ and $-100 \mathrm{~V}$ suffered from adhesive fracture in pull-off testing and early delamination in tribological testing. These results were assumed to be due to a titanium oxide layer which was not properly removed prior to the deposition of the hydrogenated amorphous carbon films and to the higher residual internal stress of the a-C:H films obtained with bias voltages of $-50 \mathrm{~V}$ and $-100 \mathrm{~V}$ compared with the two polymer-like films.

\section{KEYWORDS}

PEEK; diamond-like carbon; friction; wear; adhesion; PECVD 


\section{INTRODUCTION}

Poly-aryl-ether-ether-ketone (PEEK) is a remarkable thermoplastic polymer marked by high bulk mechanical properties and chemical inertia. This polymer material has been intensively studied over the last decades, opening success on industrial applications such as mechanical bearings [1] or seals [2]. PEEK is also known for its biocompatibility[3]. For this reason, it is a material subjected to intensive research for biomedical applications, in particular for biomedical implants, including dental implants [4] and intervertebral disc implants [5-8].

Many surface modification techniques have been investigated on biomaterials $[9,10]$. Recently, it has been attempted to modify the surface properties of PEEK via physical and/or chemical processes in order to respond to specific needs. More precisely, it is possible to increase its surface free energy via plasma treatments $[11,12]$ or to reduce wear in a selfmating contact via a laser surface texturing [13].

In particular, Diamond-like carbon (DLC) films are known to reduce friction and wear, and such films have now reached the industrial scale with mass market applications [14]. DLC films cover a wide range of mechanical and physical properties and are usually divided into four groups depending on their contents in $\mathrm{Csp}^{3}, \mathrm{Csp}^{2}$ and hydrogen. Hydrogenated amorphous carbon $(\mathrm{a}-\mathrm{C}: \mathrm{H})$ films, characterized by rather high contents in hydrogen and $\mathrm{sp}^{3}$ carbon, are one of these four groups. a-C:H films can be deposited from a hydrocarbon gas by Plasma Enhanced Chemical Vapor Deposition (PECVD) [15].

Depending on the parameters of the deposition process, a-C:H films exhibit a wide range of hardness values and hydrogen contents. When the hydrogen content is ranging between 20 and $40 \%$, the corresponding a-C:H films have a significant $\mathrm{Csp}^{3}$ content and exhibit hardness above about $10 \mathrm{GPa}$ [15]. When the hydrogen content is ranging between 40 and $50 \%$, the a$\mathrm{C}: \mathrm{H}$ films are generally softer with a hardness lower than $10 \mathrm{GPa}$ and thus called soft a-C:H 
films. Such highly hydrogenated a-C:H films, with a hydrogen content close to $50 \%$, are known as polymer-like amorphous carbon (PLC) films. These PLC films are usually crosslinked and contain a significant amount of imprisoned radicals [16].

Both hydrogen-free and hydrogenated DLC films deposited on metallic biomaterials such as CoCrMo, Ti6Al4V or 316L stainless steel, have been extensively investigated [17-19]. In biomedical applications, excellent film/substrate adhesion is a critical factor. DLC films deposited on metallic biomaterials often exhibit high compressive internal residual stress, thus, metallic interlayers are used in order to adjust the film/substrate mismatch of material behavior and achieve high adhesion [20]. Results show generally promising results in in vitro experiments of load bearing articulations as wear is significantly reduced compared with uncoated parts. Unfortunately, DLC films often suffer from in vivo long-term partial delamination due to in vivo corrosion [21-23]. More precisely, long-term partial delamination can be caused by stress corrosion cracking of the interlayer/substrate interface [17] or dissolution of an adhesion-promoting interlayer by crevice corrosion [24].

In the literature, previous works report the successful deposition of DLC films on PEEK [2529]. In particular, Kaczorowski et al. [28,29] studied the effect of various plasma etching treatments prior to the deposition of DLC films on PEEK. More precisely, they assessed the changes in surface topography, chemical composition, wetting, mechanical and tribological behaviors associated with the different plasma etching treatments. Wang et al. [27] performed the same physicochemical and mechanical characterizations of DLC coated PEEK. In addition, they performed cell culture assays and showed that osteoblast attachment, proliferation and differentiation are better on DLC coated PEEK than on PEEK.

In the present work, four different thin a-C:H films were deposited by PECVD on a PEEK polymer in order to improve its tribological performance in terms of friction and wear in physiological conditions. The objective is to characterize the mechanical and tribological 
behaviors of these different thin a-C:H films deposited on PEEK, with particular attention paid to the film/substrate adhesion.

\section{MATERIALS AND METHODS}

\subsection{Sample preparation}

The PEEK polymer is a semi-crystalline natural PEEK (Victrex PEEK 450G) and received as an injection-molded bar of $25.4 \mathrm{~mm}$ in diameter. The PEEK test samples were either machined or cut from the injection-molded bar as two sizes of samples were used: $25.4 \mathrm{~mm}$ in diameter cylindrical discs and $10 \mathrm{~mm}$ in diameter cylindrical discs. All cylindrical discs were $4 \mathrm{~mm}$ thick. The $10 \mathrm{~mm}$ in diameter discs were used to carry out the tribological tests whereas the $25.4 \mathrm{~mm}$ in diameter discs were used to carry out all the other characterizations.

The samples were polished to a mirror finish using, consecutively, different cloths soaked with a $9-\mu \mathrm{m}$ diamond paste, a $3-\mu \mathrm{m}$ diamond paste and a $0.3-\mu \mathrm{m}$ alumina suspension. The samples were cleaned in an ethanol bath and a distilled water bath under ultrasonic vibrations for 10 min before being dried with a nitrogen blast.

Prior to deposition, the PEEK samples were cleaned in a polymer-dedicated detergent bath under ultrasonic vibrations for 3 minutes before being rinsed successively in 6 water baths. The samples were then rinsed with isopropanol before being dried with a dry compressed-air blast and placed in a forced-air heating chamber at $80^{\circ} \mathrm{C}$ for 30 minutes.

The coating depositions were carried out in a PECVD reactor (TSD 550 deposition equipment, HEF group) equipped with a cathodic magnetron sputtering device.

Four different thin a-C:H films were carried out: two hydrogen-rich polymer-like films obtained without applying any bias voltage to the samples and two hydrogenated amorphous 
carbon films obtained by applying a bias voltage to a $1 \mu \mathrm{m}$ thick titanium layer which was deposited on the PEEK surface by cathodic magnetron sputtering prior to the deposition of the carbon film. Figure 1 shows the architecture of the four deposited films.

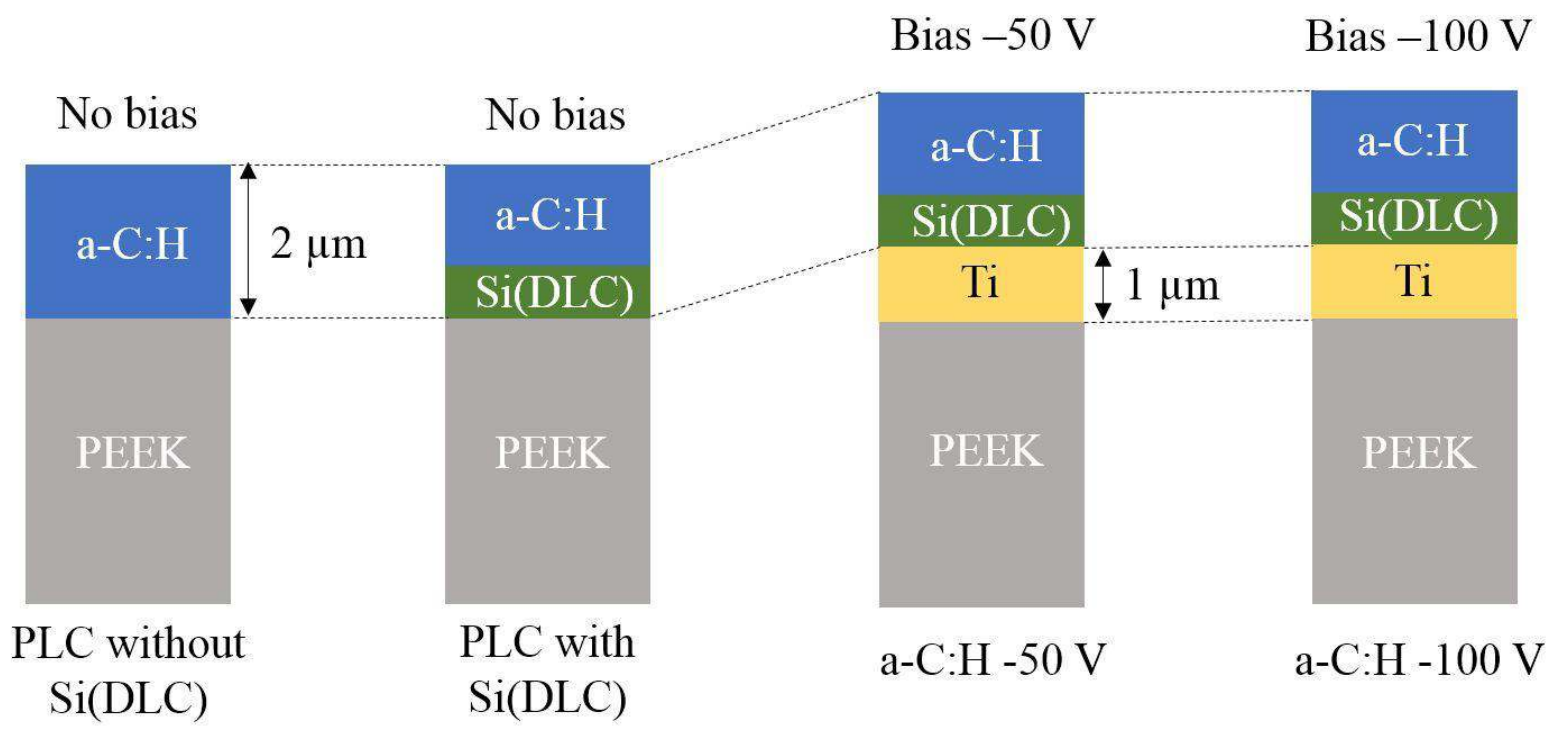

Figure 1 - Architecture of the four a-C:H films deposited on PEEK

Prior to the deposition of the titanium layer or the polymer-like carbon films, the PEEK surface was activated by an oxygen plasma treatment in order to create $\mathrm{C}-\mathrm{O}$ bonds at the PEEK surface and promote adhesion [11,30,31].

The titanium layer was deposited by cathodic magnetron sputtering in an argon atmosphere for one hour in order to obtain a $1 \mu \mathrm{m}$ thick layer. Once the titanium layer was deposited, the PECVD reactor was opened in order to make sure there was a good electrical contact between the titanium layer and the substrate holder so that a bias voltage could be efficiently applied to the surface. Once the electrical contact was ensured, the $1 \mu \mathrm{m}$ thick titanium was subject to an Ar plasma etching in order to remove the titanium oxide layer and any other contaminants.

In order to promote adhesion between the titanium layer and the a-C:H film, a silicon-doped DLC layer was deposited from a gas mixture of tetramethylsilane $\left(\mathrm{Si}\left(\mathrm{CH}_{3}\right)_{4}\right)$, acetylene 
$\left(\mathrm{C}_{2} \mathrm{H}_{2}\right)$ and argon. Then the a-C:H film was deposited from a gas mixture of acetylene and argon.

The two hydrogenated amorphous carbon films were obtained by applying a bias voltage to the titanium layer during the depositions of the amorphous carbon coating. One hydrogenated amorphous carbon film was carried out applying a DC-pulsed bias voltage of -50V to the titanium layer (hereafter designated "a-C:H -50V") and the other applying a DC-pulsed bias voltage of $-100 \mathrm{~V}$ (hereafter designated "a-C:H -100V").

For the two polymer-like carbon films, no titanium layer was deposited and no biasing was applied to the substrate holder. One of the two polymer-like films was obtained by depositing, first, a silicon-doped DLC layer followed by a a-C:H layer (hereafter designated "PLC with $\operatorname{Si}(\mathrm{DLC})$ "). The other polymer-like film was obtained by depositing only a a-C:H film made from pure hydrocarbon gas (hereafter designated "PLC without $\mathrm{Si}(\mathrm{DLC})$ "). The total thickness of the films, without the titanium layer when there was one, was $2 \mu \mathrm{m}$.

\subsection{Surface characterizations}

Atomic Force Microscopy (NanoscopeV NanoMan, Bruker Corporation) was performed in order to assess surface topography before and after film deposition. The topographical measurements were carried out in tapping mode in order to avoid a possible surface damage of the PEEK surface. The surface topography was assessed on three different $25 \mu \mathrm{m} \times 25 \mu \mathrm{m}$ areas.

The average roughness $S_{a}$, the root mean square roughness $S_{q}$ and the developed interfacial area ratio $\mathrm{S}_{\mathrm{dr}}$ were calculated according to ISO 25178. All 3D data which were collected either for topographical assessment or for wear volume measurement as described below were processed using the Altimap Premium 6.2 software (Altisurf Company). 
The wetting properties of biomaterials can influence their biotribological behavior in in vivo conditions as proteins tend to easily adsorb on surfaces[32-34]. Therefore, contact angle measurements were carried out with the help of a tensiometer (DSA30, Krüss Company) using the sessile drop method. Water, diiodomethane and ethylene glycol were used as liquids for the contact angle measurements so that the total surface free energy and its polar and dispersive components could be assessed using the Owens-Wendt formalism [35]. When depositing a droplet on the surface of the films or the substrate, the evolution of the contact angle was measured for 40 seconds so that the contact angle at equilibrium could be determined. At least five contact angle measurements per sample were performed.

The chemical structures of PLC without $\mathrm{Si}(\mathrm{DLC})$ and a-C:H $-100 \mathrm{~V}$ were analyzed using Xray Photoelectron Spectroscopy (XPS). The X-ray source was a monochromatic Al source $(\mathrm{K} \alpha=1486.6 \mathrm{eV})$. An accurate acquisition of the $\mathrm{C} 1 \mathrm{~s}$ peak was performed in order to deconvolute the contributions of the $\mathrm{sp}^{2} \mathrm{C}=\mathrm{C}, \mathrm{sp} 3 \mathrm{C}-\mathrm{C}$ and $\mathrm{C}-\mathrm{O}$ bonds. Spectra were shifted so that the C1s peak was at $284.6 \mathrm{eV}$. Gauss-Lorentz curves centered at 284.5, 285.3 and $286.1 \mathrm{eV}$ were used to deconvolute the $\mathrm{sp}^{2} \mathrm{C}=\mathrm{C}, \mathrm{sp} 3 \mathrm{C}-\mathrm{C}$ and $\mathrm{C}-\mathrm{O}$ peaks, respectively [29,36]. The C KLL Auger peaks were also studied. More precisely, the C KLL Auger spectrum was smoothed and the D parameter, which is defined as the energy difference between the maximum and minimum of the first derivative of the C KLL Auger spectrum, was measured so that the concentration of $\mathrm{sp}^{2} \mathrm{C}=\mathrm{C}$ bonds could be estimated $[29,37,38]$.

\subsection{Mechanical characterizations}

In coating applications, adhesion is a key factor to the success of the targeted application. In this work, adhesion was assessed using pull-off and scratch tests. The adhesion strength of the different films was assessed using a pull-off adhesion tester (Positest AT-M, DeFelsko Corporation). An epoxy resin was used to attach $10 \mathrm{~mm}$ in diameter pins to the film and was cured for 2 hours at $80^{\circ} \mathrm{C}$. The loading rate was between 0.20 and $0.25 \mathrm{MPa} / \mathrm{s}$ during the test. 
The pull-off stress applied to the film was monitored in real-time and the maximum pull-off stress was recorded. The pull-off tests were duplicated for each film condition.

In order to assess the cohesion and adhesion of the films, scratch tests (P2M platform, EQUIPEX MANUTECH-USD) were performed using a Rockwell C diamond tip with a tip curvature of $200 \mu \mathrm{m}$. The tip speed was constant along the scratch and set at $10 \mathrm{~mm} . \mathrm{s}^{-1} .3 \mathrm{~mm}$ long scratches were performed at constant normal force. Scratches at different normal forces between 0.5 and $10 \mathrm{~N}$ were carried out. The lower normal load (critical load) at which the film was either severely damaged (cohesion failure) or delaminated (adhesive failure) was determined via a postmortem analysis performed with the help of an optical microscope. The scratch tests were duplicated for each film condition.

Evaluating the internal residual stress of a coating can provide useful information on its mechanical behavior. PEEK beams, each 1 by $1 \mathrm{~mm}$ and $20 \mathrm{~mm}$ long, were cut from the injection-molded bar and coated on one side in order to estimate the residual internal stress in the coating using Stoney's method. The difference in the curvature of beam before and after film deposition was measured by scanning white light interferometry (Brucker Contour GTK1, Brucker Corporation) equipped with a $5 \times$ Michelson objective and a $0.5 \times$ lens defining up to eight $2.40 \mathrm{~mm} \times 2.0 \mathrm{~mm}$ areas, which were stitched subsequently. The residual internal stress was then assessed using the following expression [39,40]:

Where $\Delta \mathrm{c}$ is the difference in the curvature of the beam before and after film deposition, $\mathrm{E}_{\mathrm{s}}$ and $v_{\mathrm{s}}$ are the elastic modulus and Poisson coefficient of the PEEK, $\mathrm{h}_{\mathrm{s}}$ the substrate thickness and $h_{\mathrm{f}}$ the film thickness. Two PEEK beams were coated for each film condition.

A nanoindenter (Universal Nanomechanical Tester, Advanced Surface Mechanics GmbH) equipped with a Vickers tip was used in order to determine the hardness and the Young's 
modulus of the films. The continuous stiffness measurement (CSM) mode was used, the loading curve was quadratic and the maximum normal load applied was $200 \mathrm{mN}$. The amplitude of the oscillations of the tip ranged between 5 and $15 \mathrm{~nm}$. Seven indentations were carried out for each film. The hardness and Young's modulus were then calculated using the Oliver and Pharr method [41]. The calculated values of hardness and reduced Young's modulus corresponded to indentation depths ranging from $50 \mathrm{~nm}$ to $5 \mu \mathrm{m}$. The hardness and reduced Young's modulus of the films were taken at an indentation depth of $100 \mathrm{~nm}$, so that the effects of surface roughness and tip defects, as well as the effect of the underlying substrate, would be negligible.

\subsection{Tribological testing}

The tribological performance of the different films was assessed using a custom-made tribometer in a ball-on-disc configuration. A 25.4-mm alumina ball was rubbed against the hydrogenated amorphous carbon films or against PEEK in reciprocating sliding. The tribological tests were triplicated. The stroke length was $5 \mathrm{~mm}$, the frequency was set at $1 \mathrm{~Hz}$ therefore the average velocity was $10 \mathrm{~mm} / \mathrm{s}$. The test duration was 30000 cycles so that the total sliding distance was $300 \mathrm{~m}$. To simulate physiological conditions, the tribosystem was immersed in a solution of bovine calf serum and maintained at $37^{\circ} \mathrm{C}$ during the test. The bovine calf serum solution was obtained from a commercial solution of bovine calf serum of known protein (albumin and globulins) concentration. The protein concentration was adjusted by addition of distilled water so that the final protein concentration was $30 \mathrm{~g} / \mathrm{L}$. The normal force was set and regulated at $20 \mathrm{~N}$. According to Hertz theory and considering a PEEK/alumina contact, the mean contact pressure was 52.5 MPa so that the maximum contact pressure was below the elastic yield stress of the PEEK, which is about $90 \mathrm{MPa}$. Both normal 
and tangential forces were recorded over a full cycle every ten cycles so that the coefficient of friction could be calculated.

Wear volumes were assessed using scanning green light interferometry. A $5 \times$ Michelson objective and a $1 \times$ lens were used defining up to eighteen $1.2 \mathrm{~mm} \times 1.0 \mathrm{~mm}$ areas, which were subsequently stitched. Scanning electron microscopy (SEM) as well as energy-dispersive Xray spectroscopy (EDX) were performed. Prior to SEM observation, an electrically conductive coating was deposited by low-vacuum sputter coating from a gold/palladium alloy. 


\section{EXPERIMENTAL RESULTS}

\subsection{Surface characterization of the substrate and the coatings}

Table 1 presents the surface roughness parameters of the four a-C:H films. A polished PEEK reference has been added. After polishing the PEEK surface is very smooth as it can be seen on the values of the average roughness, root mean square roughness and, particularly, the developed interfacial area ratio $S_{\mathrm{dr}}$ as it is very close to zero. After film deposition, the average roughness ranges from 10.1 to $16.4 \mathrm{~nm}$, the root mean square ranges from 14.3 to $21.9 \mathrm{~nm}$ and the developed interfacial area ratio ranges from 1.160 to $2.480 \%$ which means that there is a clear increase in surface roughness compared with the PEEK substrate surface. Figure 2 (a) presents the surface topography of the PEEK surface which is very smooth compared with the surface topography of the coatings which has small clusters significantly increasing its roughness (Figure $2(b))$.

\begin{tabular}{|l|l|l|l|l|l|}
\hline $\begin{array}{l}\text { Roughness } \\
\text { parameters } \\
\text { according to } \\
\text { ISO 25178 }\end{array}$ & PEEK & $\begin{array}{l}\text { PLC without } \\
\text { Si(DLC) }\end{array}$ & $\begin{array}{l}\text { PLC with } \\
\text { Si(DLC) }\end{array}$ & a-C:H -50V & $\begin{array}{l}\text { a-C:H - } \\
100 \mathrm{~V}\end{array}$ \\
\hline $\mathrm{S}_{\mathrm{a}}(\mathrm{nm})$ & $6.5(1.0)$ & $12.2(1.6)$ & $16.4(1.9)$ & $10.1(1.1)$ & $15.6(0.6)$ \\
\hline $\mathrm{S}_{\mathrm{q}}(\mathrm{nm})$ & $8.3(1.0)$ & $15.8(2.2)$ & $21.9(2.9)$ & $14.3(1.6)$ & $20.5(1.6)$ \\
\hline $\mathrm{S}_{\mathrm{dr}}(\%)$ & $0.116(0.039)$ & $1.620(0.425)$ & $2.480(0.399)$ & $\begin{array}{l}1.160 \\
(0.402)\end{array}$ & $\begin{array}{l}1.980 \\
(0.046)\end{array}$ \\
\hline
\end{tabular}

Table 1 - Surface roughness parameters $S_{\mathrm{a}}, \mathrm{S}_{\mathrm{q}}$ and $\mathrm{S}_{\mathrm{dr}}$ of the PEEK surface after polishing and the four a-C:H films (values in parentheses are standard deviations) 


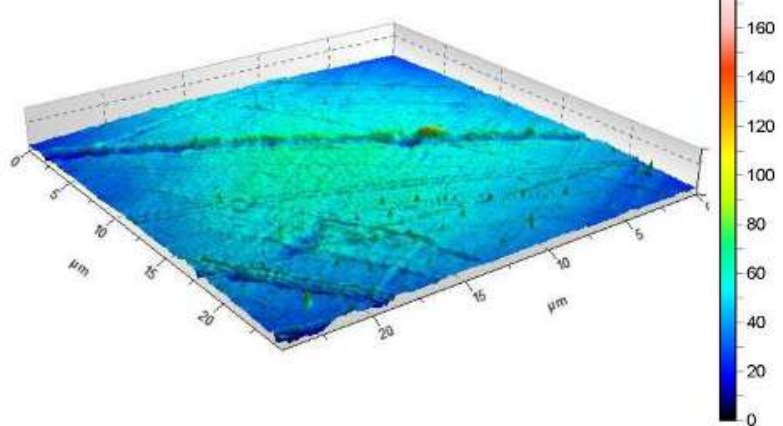

(a)

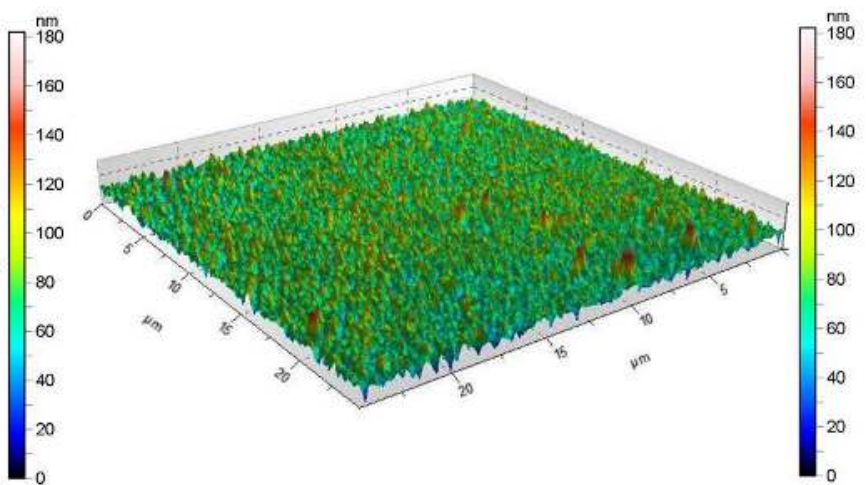

(b)

Figure 2 - Surface topographies of (a) the polished PEEK substrate and (b) the PLC coating without the Si-doped DLC underlayer

Figure 3 presents the dispersive and polar components of the surface free energies of the PEEK substrate and the four a-C:H films as well as their respective water contact angles. The total surface free energy of the PEEK substrate is $44.3 \mathrm{~mJ} / \mathrm{m}^{2}$. After film deposition, the surface free energy increases and ranges from $53.0 \mathrm{~mJ} / \mathrm{m}^{2}$ to $57.2 \mathrm{~mJ} / \mathrm{m}^{2}$. The dispersive component of the surface free energy of the four hydrogenated amorphous carbon films is high and almost the same from one coating to another, ranging from 43.2 to $45.6 \mathrm{~mJ} / \mathrm{m}^{2}$. As a consequence, the contact angles for diiodomethane are low and range from 7 to $15^{\circ}$.

Among the four a-C:H films, only the water contact angle is different. It ranges from 50 to $65^{\circ}$. While the dispersive component of the surface free energy of the four hydrogenated amorphous carbon coatings are almost identical, the polar component of the surface free energy varies from one coating to another and ranges from 7.4 to $14.0 \mathrm{~mJ} / \mathrm{m}^{2}$. 


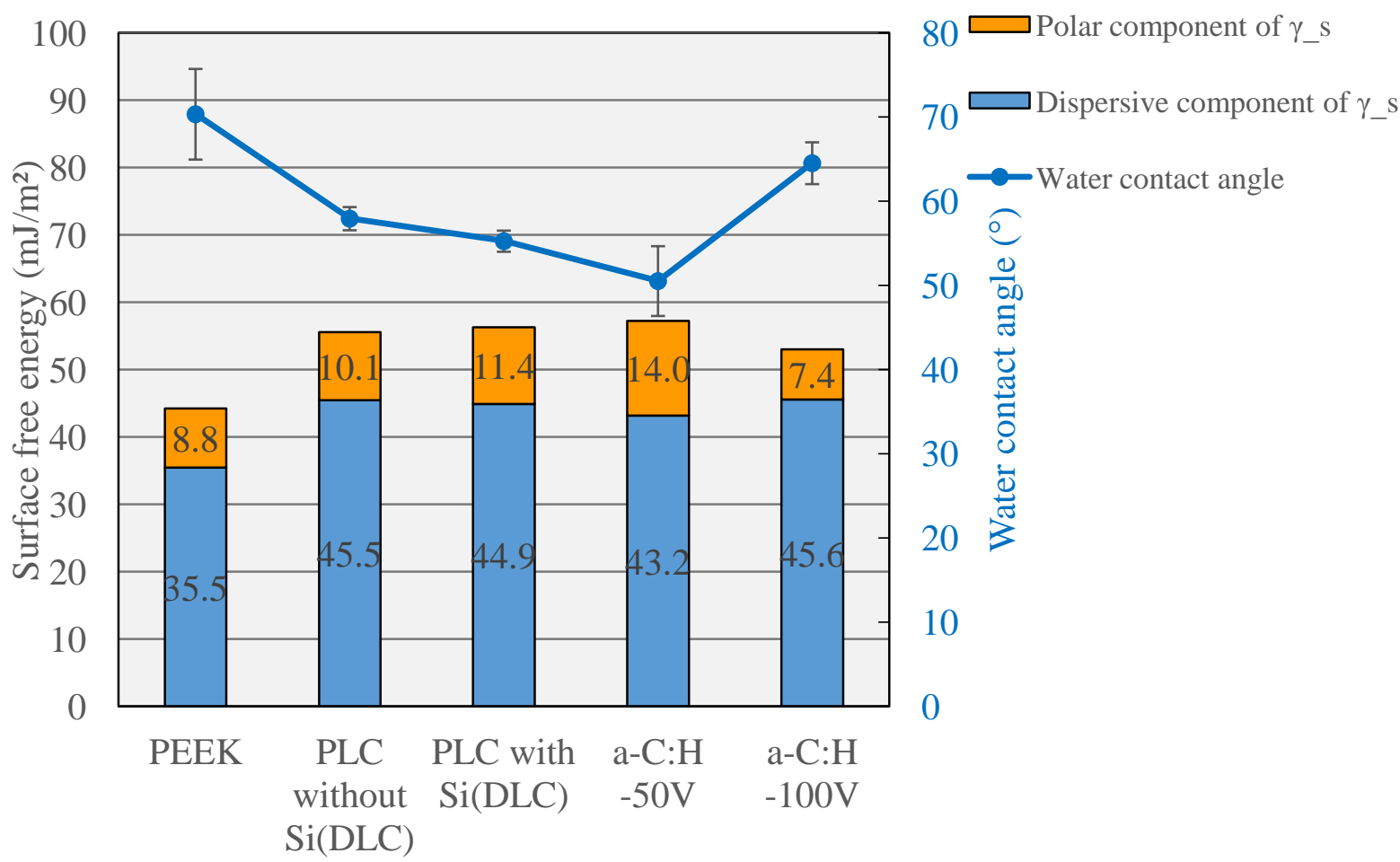

Figure 3 - Dispersive and polar components of the surface free energies and water contact angles of the PEEK and the four hydrogenated amorphous carbon films (error bars are standard deviations)

XPS results show that PLC without $\mathrm{Si}(\mathrm{DLC})$ and a-C:H $-100 \mathrm{~V}$ exhibit slight differences in term of elemental compositions and contents in $\mathrm{sp}^{2} \mathrm{C}=\mathrm{C}$ and $\mathrm{sp}^{3} \mathrm{C}-\mathrm{C}$ bonds as shown in Table 2. In particular, the oxygen contents of PLC without $\mathrm{Si}$ (DLC) and a-C:H $-100 \mathrm{~V}$ are 13.6 and $8.4 \%$, respectively. Based on the deconvolution of the $\mathrm{sp} 2 \mathrm{C}=\mathrm{C}$ and $\mathrm{sp} 3 \mathrm{C}-\mathrm{C}$ bond contributions to the $\mathrm{C} 1 \mathrm{~s}$ peak (Figure 4), the sp3/sp2 ratios of PLC without $\mathrm{Si}(\mathrm{DLC}$ ) and a$\mathrm{C}: \mathrm{H}-100 \mathrm{~V}$ are 0.32 and 0.39 , respectively.

The concentration of $\mathrm{sp}^{2} \mathrm{C}=\mathrm{C}$ bonds was also assessed by determining the $\mathrm{D}$ parameter. The D parameter values were $16.3 \mathrm{eV}$ and $15.8 \mathrm{eV}$ for PLC without $\mathrm{Si}(\mathrm{DLC})$ and a-C:H $-100 \mathrm{~V}$, respectively. Based on a linear interpolation of the D-parameter, which is supposed to be equal to $13.7 \mathrm{eV}$ for diamond $\left(0 \% \mathrm{sp}^{2} \mathrm{C}=\mathrm{C}\right.$ bonds) and $21.2 \mathrm{eV}$ for graphite $\left(0 \% \mathrm{sp}^{2} \mathrm{C}=\mathrm{C}\right.$ 
bonds) according to the literature [38], the contents in $\mathrm{sp}^{2} \mathrm{C}=\mathrm{C}$ bonds were 34.2 and $27.3 \%$ for PLC without $\mathrm{Si}(\mathrm{DLC})$ and a-C:H $-100 \mathrm{~V}$, respectively.

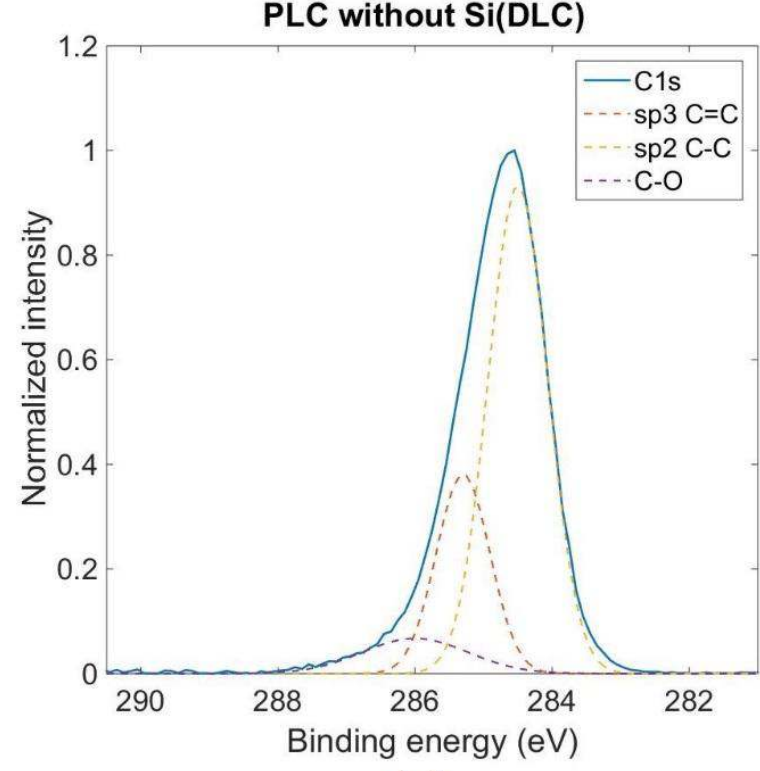

(a)

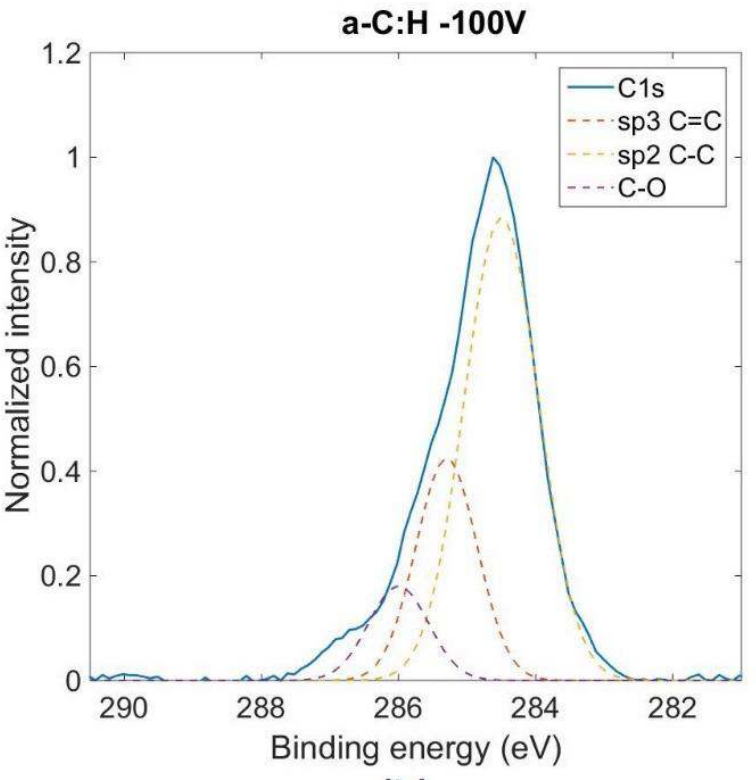

(b)

Figure $4-\mathrm{C} 1$ s spectra and deconvolutions of (a) PLC without Si(DLC) and (b) a-C:H -100V

\begin{tabular}{|l|l|l|l|l|l|}
\hline & \multicolumn{4}{l|}{$\begin{array}{l}\text { Concentration of element } \\
\text { (at. \%) }\end{array}$} & \multicolumn{3}{l|}{ Area percentage of C1s peak (\%) } \\
\hline Coating & C1s & O1s & sp2 C=C & sp3 C-C & C-O \\
\hline PLC without $\mathrm{Si}$ (DLC) & 86.4 & 13.6 & 64.5 & 20.4 & 15.1 \\
\hline a-C:H -100V & 91.6 & 8.4 & 65.3 & 25.5 & 9.3 \\
\hline
\end{tabular}

Table 2 - Concentration of carbon and oxygen in the coatings based on the $\mathrm{C} 1 \mathrm{~s}$ and $\mathrm{O} 1 \mathrm{~s}$ peak intensities and contributions of $\operatorname{sp} 2 \mathrm{C}=\mathrm{C}, \mathrm{sp} 3 \mathrm{C}-\mathrm{C}$ and $\mathrm{C}-\mathrm{O}$ bonds to the $\mathrm{C} 1 \mathrm{~s}$ peak

\subsection{Mechanical properties of the coatings}

Figure 5 presents the results of the nanoindentation experiments on the PEEK substrate and the four hydrogenated amorphous carbon films in terms of surface indentation hardness and reduced Young's modulus. 
The indentation hardness of PEEK is $0.34 \mathrm{GPa}$. The two polymer-like carbon coatings enabled to multiply the surface indentation hardness by a factor of ten. Indeed the indentation hardness values of the polymer-like coatings with and without the Si-doped DLC underlayer are respectively 3.2 and 3.6 GPa. The increase in surface indentation hardness is even larger when the surface of the sample is biased thanks to the titanium layer: for the a-C:H with bias voltages of $-50 \mathrm{~V}$ and $-100 \mathrm{~V}$, the indentation hardness values are respectively 5.1 and $5.2 \mathrm{GPa}$. Thus, there is a 15-fold increase in indentation hardness compared with that of PEEK. The same trend is observed in terms of reduced Young's modulus. The reduced Young's modulus increases from 5.9 GPa to 21-24 GPa for the two polymer-like carbon coatings. The increase in reduced Young's modulus is also larger for the hydrogenated amorphous carbon coatings obtained with biasing of the titanium underlayer: with an applied bias voltage of $-50 \mathrm{~V}$ the reduced Young's modulus is $34.7 \mathrm{GPa}$ and with an applied bias voltage of $-100 \mathrm{~V}$ the reduced Young's modulus is $37.5 \mathrm{GPa}$. 

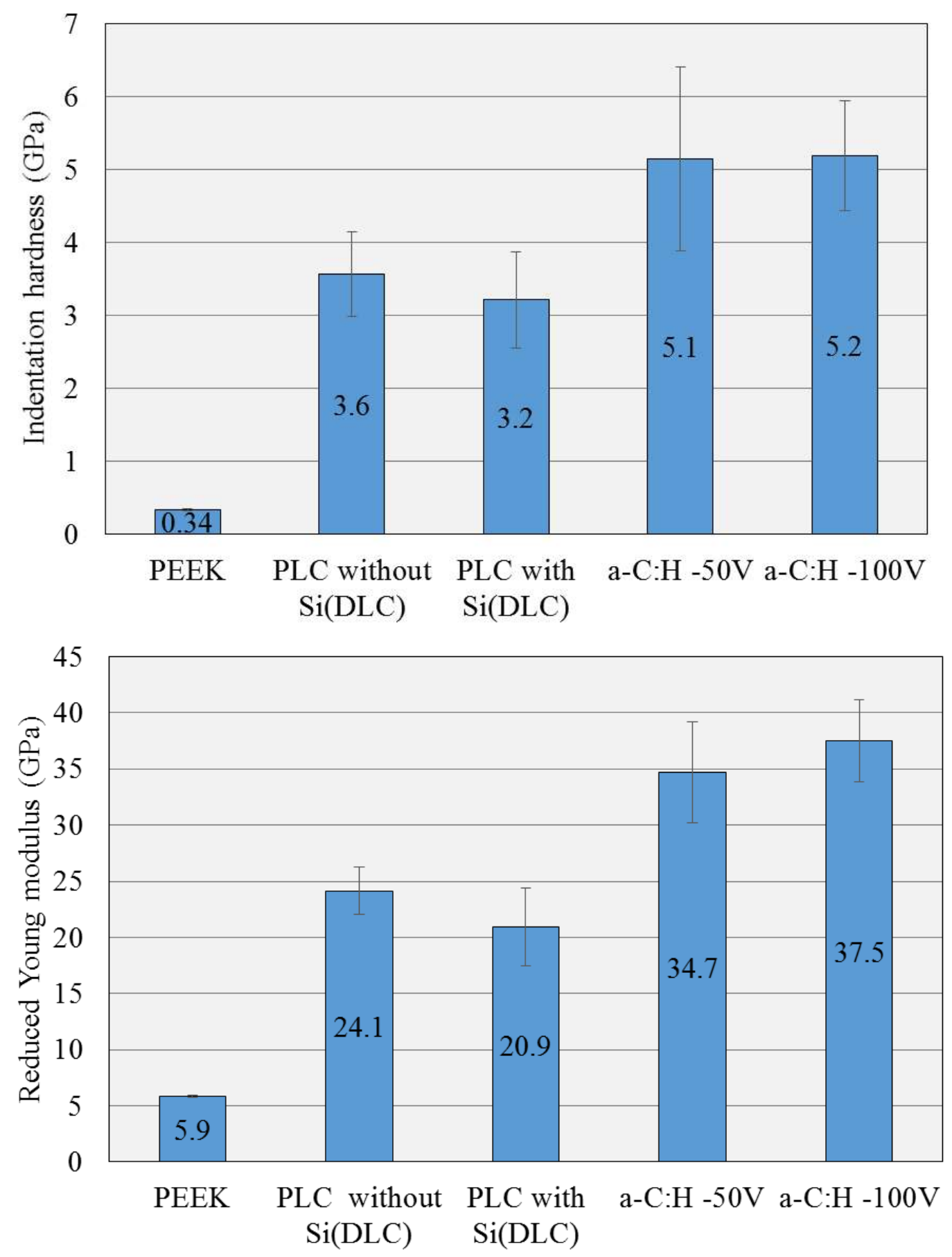

Figure 5 - Indentation hardness (top) and reduced Young's moduli (bottom) of the PEEK substrate and the four hydrogenated amorphous carbon films (error bars are standard deviations)

Figure 6 presents the residual internal stress measured thanks to Stoney's method as a function of the bias voltage applied during the deposition of the a-C:H films. The two polymer-like carbon are much less internally stressed than the two a-C:H coatings which are 
obtained with biasing. The compressive internal stress ranges from -150 to $-230 \mathrm{MPa}$ for the two polymer-like carbon coatings while it ranges from -540 to $-700 \mathrm{MPa}$ for the two a-C:H coatings obtained with biasing.

- Applied bias voltage (V)

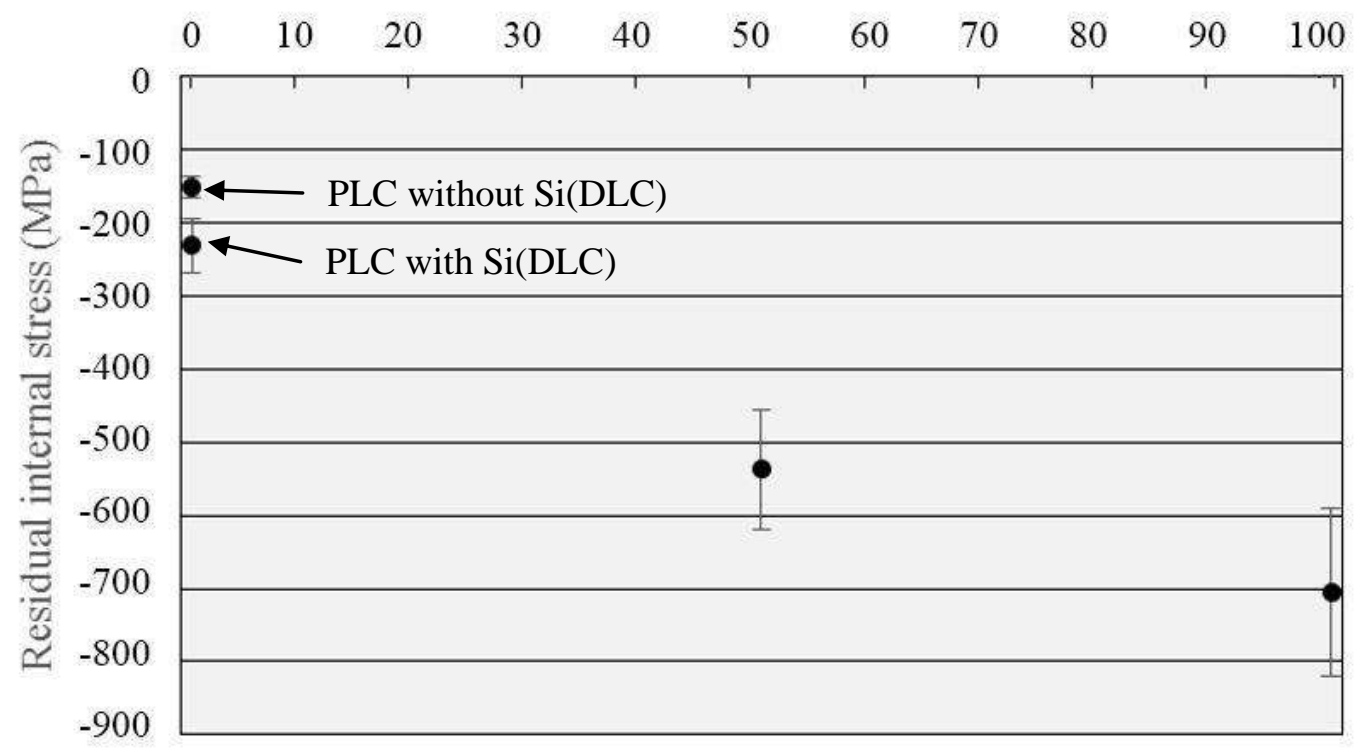

Figure 6 - Residual internal stress as a function of the applied bias voltage for the four a-C:H carbon films (error bars are standard deviations)

Table 3 summarizes the mechanical data recorded during the pull-off test of the four a-C:H coatings as well as the fracture types. Both polymer-like carbon films have a maximum pulloff force of about $1400-1500 \mathrm{~N}$ and show a very high adhesion to the PEEK surface as there is a cohesive fracture in the PEEK substrate. As a result of this cohesive fracture, the maximum adhesion stress cannot be calculated. The two a-C:H films obtained with biasing are both subject to an adhesive fracture at the Ti/Si-doped DLC interface. The maximum pulloff forces are 980 and $1390 \mathrm{~N}$ for the a-C:H films obtained with bias voltages of $-50 \mathrm{~V}$ and $100 \mathrm{~V}$, respectively. Their respective maximum adhesion stress are 12.5 and $17.7 \mathrm{MPa}$. 


\begin{tabular}{|c|c|c|c|c|}
\hline & $\begin{array}{c}\text { PLC without } \\
\text { Si(DLC) }\end{array}$ & PLC with Si(DLC) & a-C:H -50V & a-C:H -100V \\
\hline $\begin{array}{c}\text { Loading speed } \\
\text { (MPa/s) }\end{array}$ & 0.25 & 0.25 & 0.20 & 0.20 \\
\hline $\begin{array}{c}\text { Maximum pull- } \\
\text { off force (N) }\end{array}$ & $1480(96)$ & $1390(130)$ & $980(410)$ & $1390(74)$ \\
\hline $\begin{array}{c}\text { Maximum } \\
\text { adhesion stress } \\
\text { (MPa) }\end{array}$ & -- & - & $12.5(5.2)$ & $17.7(0.9)$ \\
\hline $\begin{array}{c}\text { Cohesive in the } \\
\text { PEEK }\end{array}$ & $\begin{array}{c}\text { Cohesive in the } \\
\text { PEEK }\end{array}$ & $\begin{array}{c}\text { Adhesive at the } \\
\text { Ti/Si(DLC) } \\
\text { interface }\end{array}$ & $\begin{array}{c}\text { Adhesive at the } \\
\text { Ti/Si(DLC) } \\
\text { interface }\end{array}$ \\
\hline
\end{tabular}

Table 3 - Maximum pull-off forces and stress and fractures types of the pull-off testing of the four hydrogenated amorphous carbon films (values in parentheses are standard deviations) 


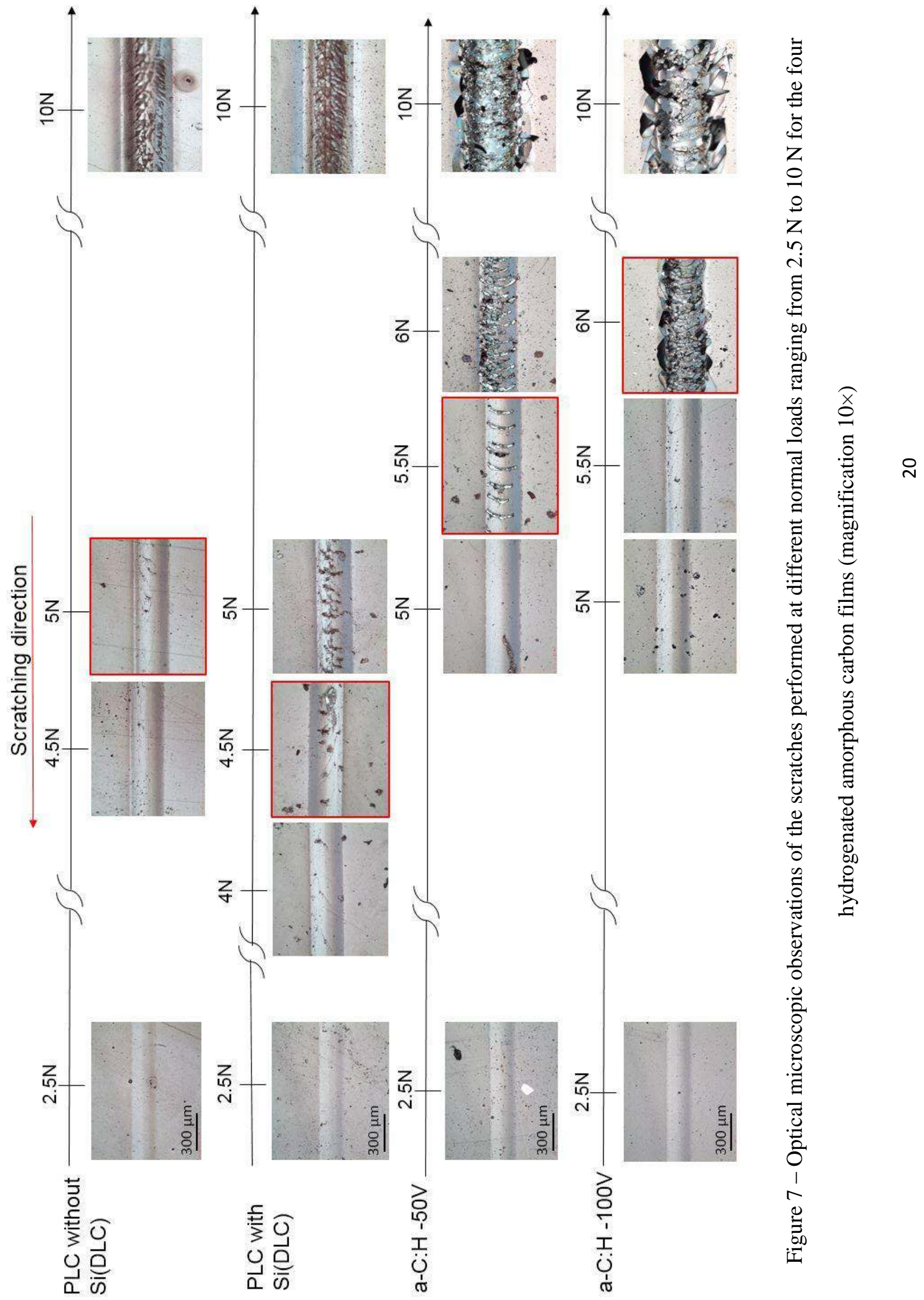


Figure 7 presents the optical microscopic observations of the scratch tests performed on the four hydrogenated amorphous carbon films at normal forces ranging from $2.5 \mathrm{~N}$ to $10 \mathrm{~N}$.

At low normal loads below $4.5 \mathrm{~N}$, for the four films, there is a plastic deformation of the PEEK substrate without any damage to the coatings. All the four hydrogenated amorphous carbon films fail at normal loads lying between 4.5 and $6 \mathrm{~N}$. However, different modes of failure are observed. For the two polymer-like coatings, the failure of the coating is due to multiple conformal cracking, that is to say, the large deformation of the PEEK substrate and the good adhesion of the coating to the substrate caused the cracking of the coating given that it cannot undergo such a large deformation. Even though the failure of the two polymer-like carbon coatings is reached at a normal load of $5 \mathrm{~N}$, the coatings are still partially adhering to the PEEK in the scratch at a normal load of $10 \mathrm{~N}$.

The situation is different for the two a-C:H coatings obtained with a bias voltage applied to the surface during the process. The a-C:H film obtained with an applied bias voltage of $-50 \mathrm{~V}$ shows chipping at $5.5 \mathrm{~N}$ and spallation of the coating at higher normal loads. The a-C:H film obtained with an applied bias voltage of $-100 \mathrm{~V}$ does not show chipping and directly starts to fail by spallation of the coating at $6 \mathrm{~N}$. At a normal load of $10 \mathrm{~N}$, the two a-C:H films obtained with biasing show delamination of large flakes of coating [42].

The failure by spallation of the two a-C:H films obtained with biasing compared with the failure by multiple conformal cracking of the two polymer-like coatings also shows that the adhesion of the two a-C:H films obtained with biasing is lower than that of the two polymerlike carbon coatings. 


\subsection{Tribological performance of the coatings}

Figure 8 (a) presents the evolution of the coefficient of friction of the PEEK and the four hydrogenated amorphous carbon films when rubbed against alumina. The coefficient of friction of the PEEK/alumina couple increases from 0.16 at the beginning of the test to 0.35 after 15000 cycles and then stabilizes. Before its stabilization, the coefficient of friction is fluctuating from one cycle to the other but after 15000 cycles it is relatively smooth.

The two polymer-like coatings have the same behavior in terms of coefficient of friction showing relatively low values. At the beginning of the test, the coefficient of friction is about 0.2 then it reaches a lower minimum value before slowly increasing to reach 0.23 at the end of the test. The overall evolution of the friction coefficient is smoother than that of the PEEK substrate as it can be observed in Figure 8.

On the other hand, the two a-C:H films obtained with biasing do not show a smooth overall evolution of the friction coefficient. Actually, for these two films, the friction coefficient is very fluctuating even though the coefficient of friction at the end of the tribological testing, it is comparable to that of the two polymer-like carbon coatings. In Figure 8 (b), the friction coefficient of the two a-C:H films obtained with biasing shows an increase at the beginning of the test until about 300 cycles where a disturbance in the evolution of the coefficient of friction is observed. On other specimen, the tribological testing was stopped right after this disturbance occurred; so it could be established that this disturbance is caused by the beginning of an early delamination of the coating as it is shown in Figures 9 (a) and (b). The elemental mapping in Figure 9 (c) shows areas where the a-C:H film was removed but not the titanium layer. Figure 9 (d) exhibits oxygen-rich areas where PEEK is exposed (PEEK has three oxygen atoms per monomer unit) and both the a-C:H film and titanium layer were removed. Therefore, delamination can occur not only at the titanium/silicon-doped DLC interface but also at the titanium/PEEK interface. 


\section{ACCEPTED MANUSCRIPT}
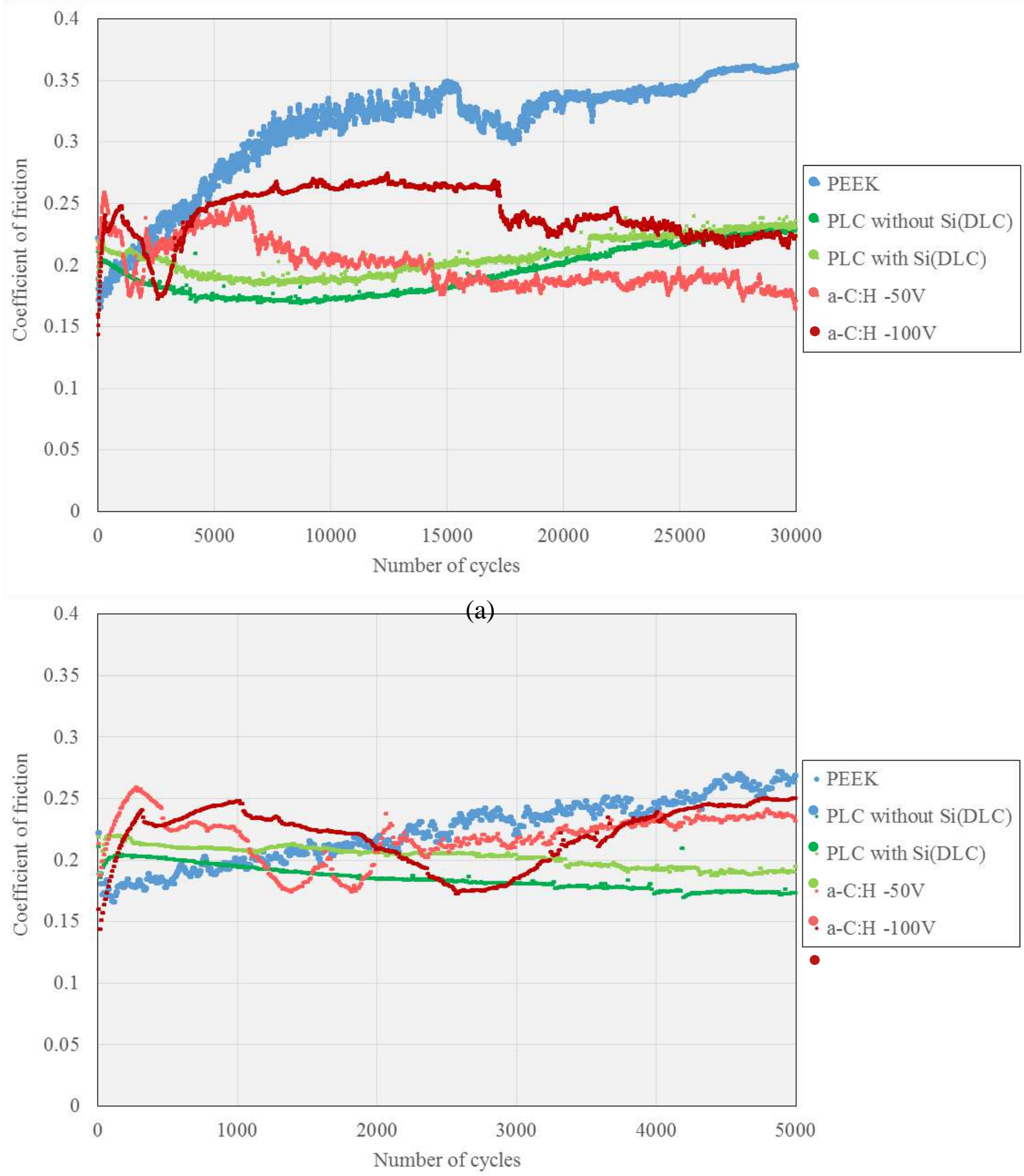

(b)

Figure 8 - (a) Evolution of the coefficient of friction of the PEEK surface and the four hydrogenated amorphous carbon films rubbed against alumina for 30000 cycles, (b) zoom on the first 5000 cycles of the coefficient of friction of the PEEK surface and the four hydrogenated amorphous carbon films 


\section{ACCEPTED MANUSCRIPT}

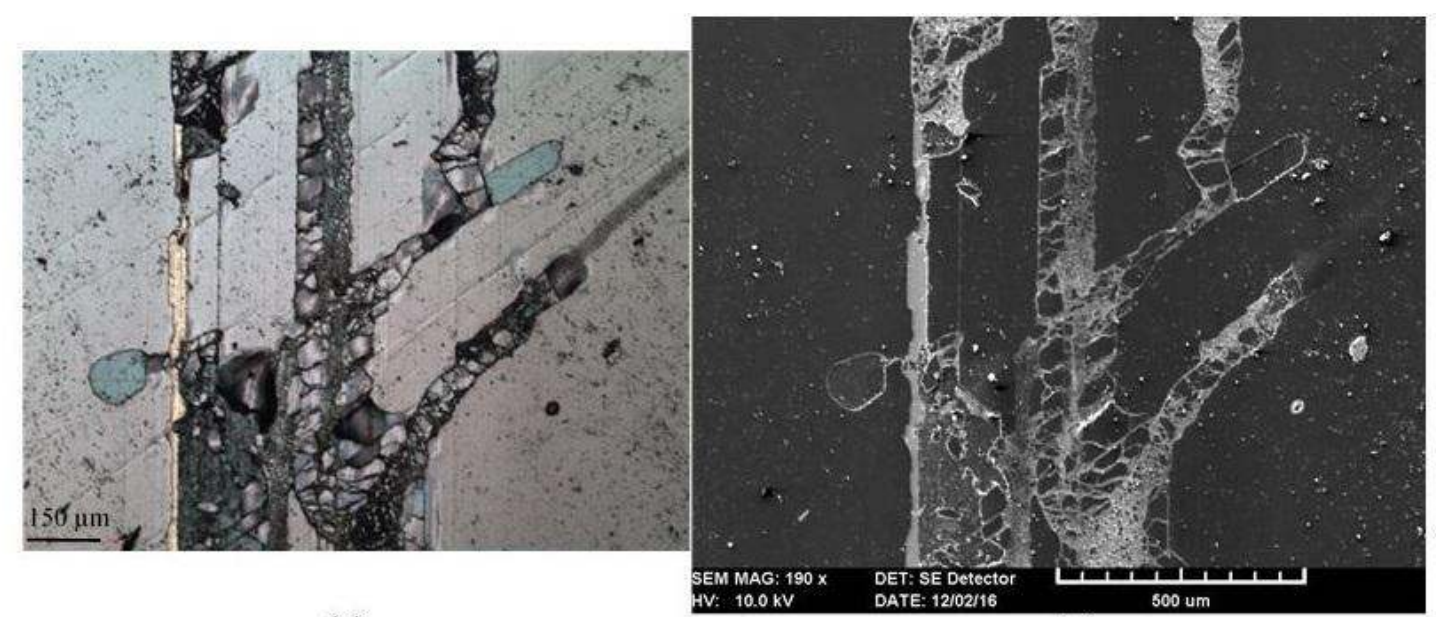

(a)

(b)

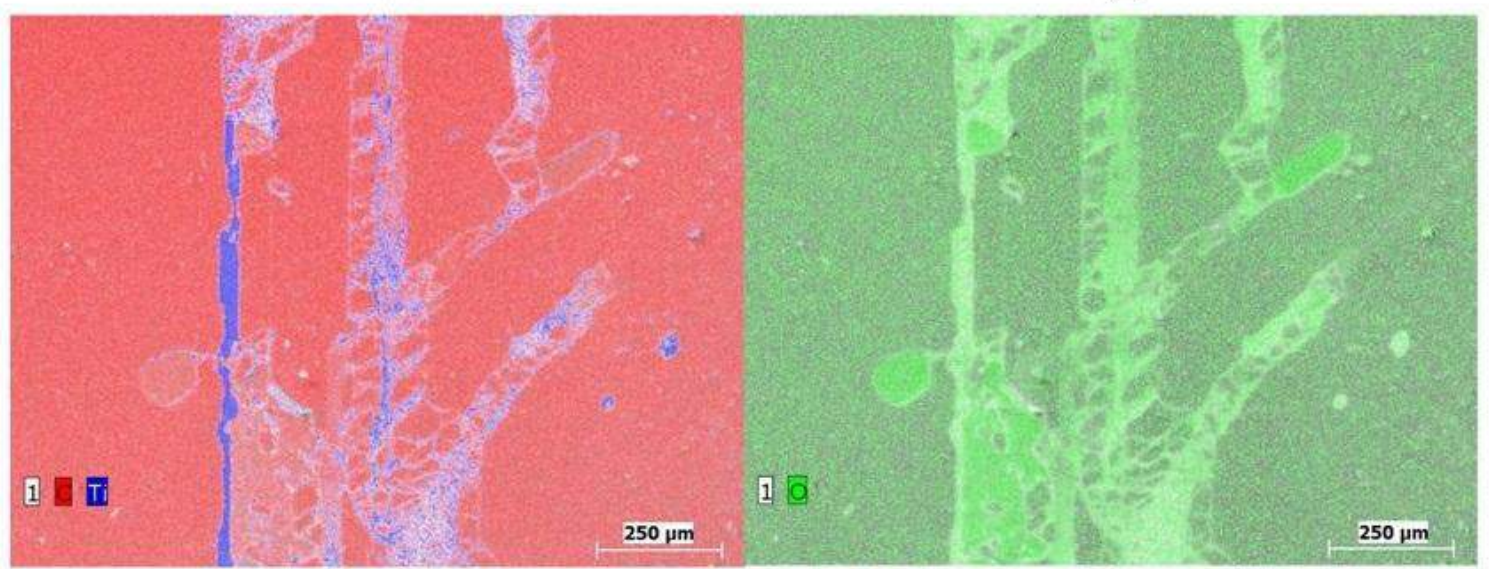

(c)

(d)

Figure 9 - Observation of the early delamination of the a-C:H film obtained with an applied bias voltage of $-50 \mathrm{~V}$ after 300 cycles by (a) optical microscopy (magnification 10x), (b) scanning electron microscopy (magnification 190x), (c) EDX elemental mapping of carbon (red) and titanium (blue), (d) EDX elemental mapping of oxygen

The uncoated PEEK shows a very large amount of wear $\left(5.1 \times 10^{8} \mu \mathrm{m}^{3}\right)$ after 30000 cycles which leads to a wear rate of $8.5 \times 10^{-5} \mathrm{~mm}^{3} \mathrm{~N}^{-1} \mathrm{~m}^{-1}$ according to Archard's approach. The two a-C:H films obtained with biasing start to delaminate after only a few hundred cycles during the tribological testing. This early delamination leads to a complete delamination of the coatings after a few thousand cycles. Therefore, after 30,000 cycles the amount of wear is also very high and comparable to that of the uncoated PEEK as shown in Figure 10. Figure 11 (c) and (d) present the wear scars of the two a-C:H coatings obtained with biasing as topographical images and optical microscopic observations. 
The two polymer-like carbon coatings show a significant decrease in wear volume. The polymer-like carbon without the Si-doped DLC underlayer shows an almost 10000-fold decrease in wear volume. It is still perfectly adherent to the PEEK substrate and shows almost no wear as it can be observed in Figure 11 (a). The polymer-like carbon film with the Sidoped DLC underlayer also shows low wear compared with PEEK. Actually, at the end of the tribological testing, this coating tends to slightly delaminate. This slight delamination, shown in Figure 10 (b), is very local as the rest of the coating shows also no wear.

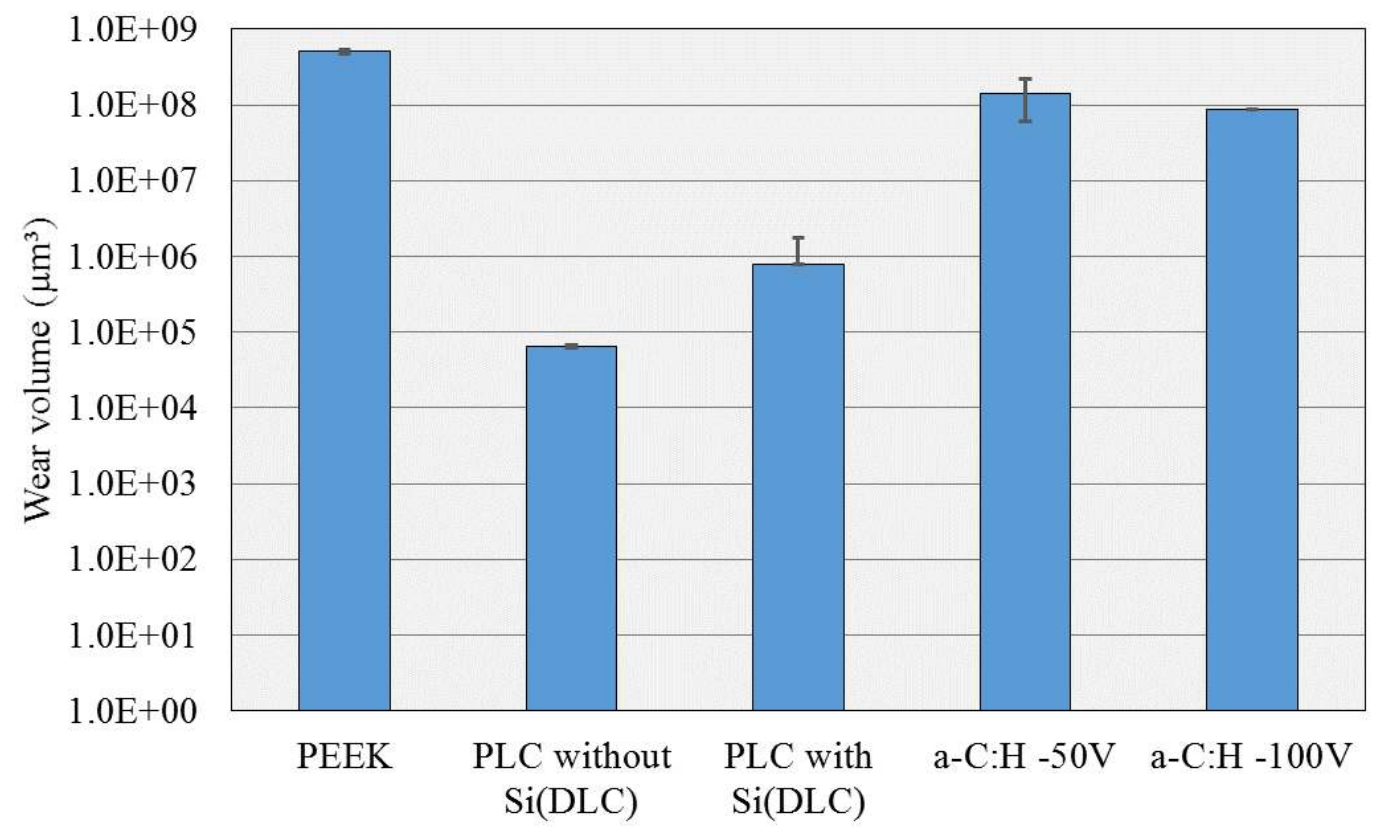

Figure 10 - Wear volumes of the PEEK substrate and the four hydrogenated amorphous carbon films after rubbing against alumina for 30000 cycles (error bars are standard deviations) 


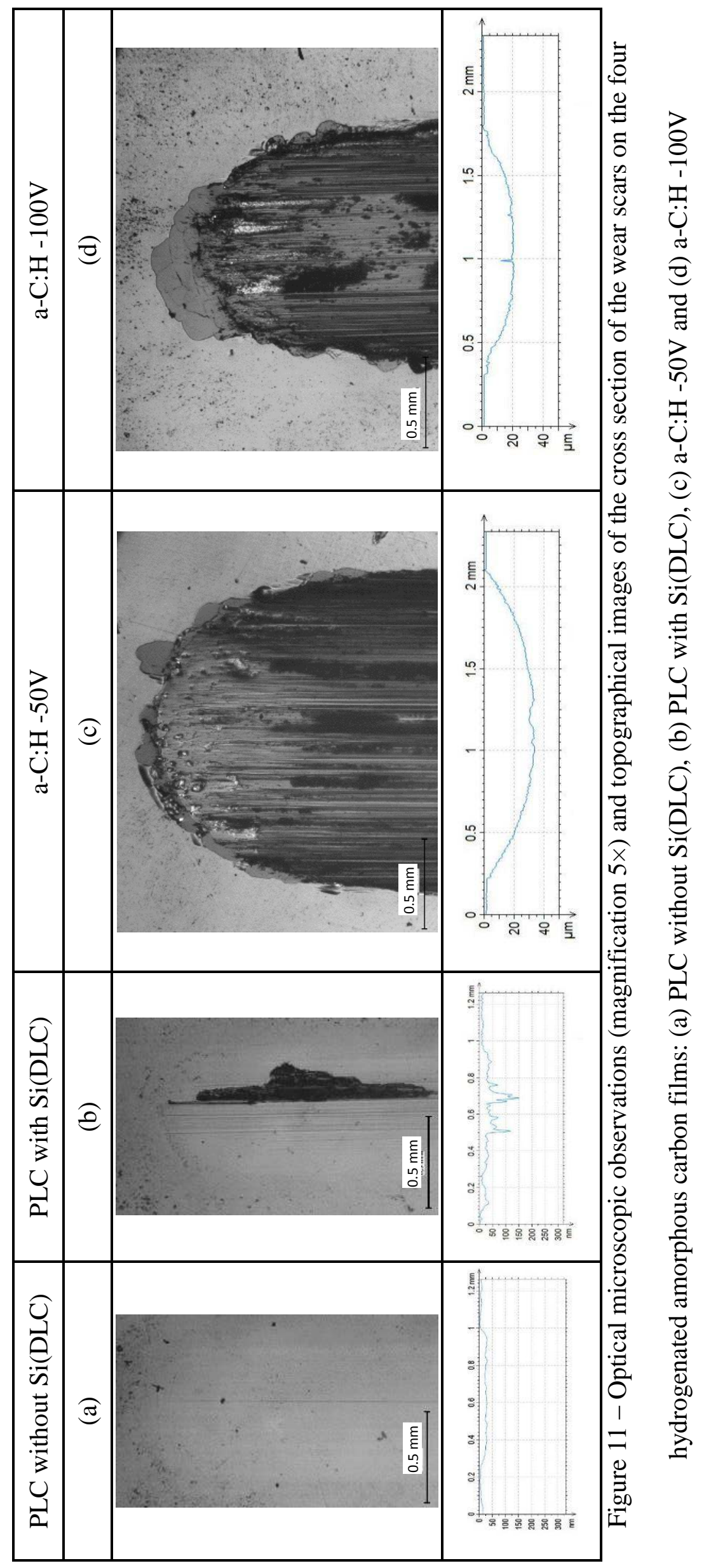




\section{DISCUSSION}

\subsection{Influence of the deposition process on the surface properties of the different coatings}

There was an increase in surface roughness after film deposition compared with that of the polished PEEK substrate. Kaczrowoski et al. [29] showed that an oxygen plasma treatment can cause an increase in surface roughness as it actually etched the PEEK surface. In this work, the oxygen plasma treatment was performed at low power for a short time, and thus not significantly increasing the surface roughness. The oxygen plasma treatment only aimed at creating dangling bonds and $\mathrm{C}-\mathrm{O}$ bonds at the PEEK surface. The increase in surface roughness after film deposition is due to the initial PEEK surface, which was very smooth, and the growth and morphology of the films. The deposition process was performed at low temperature (below $60^{\circ} \mathrm{C}$ ), hence, the condensable species of the plasma could barely diffuse at the surface and formed asperities.

As proteins tend to easily and strongly adsorb on biomaterials such as DLC films, alumina or PEEK [33,34], the wetting properties of PEEK and the four a-C:H films require discussion. The water contact angle for the PEEK surface was in accordance with what could be observed in the literature $[11,12]$. It has been shown that the dispersive component of the surface free energy of DLC coatings is not dependent on the bias voltage applied during the process [43] nor on doping [44] (except for fluorine doping [35]). Only the polar component is supposed to be affected by such a change. In the present work, the four hydrogenated amorphous carbon coatings have almost the same value of dispersive component of the surface free energy and it is rather high compared to what can be found in the literature $[43,44]$. Among the three liquids which were used for the assessment of the wetting properties of the surfaces, water has the largest polar component of surface tension. As a consequence, the water contact angle is the lowest for the coating with the highest polar component of surface free energy. The water contact angles of the four hydrogenated amorphous carbon coatings deposited on PEEK in the 


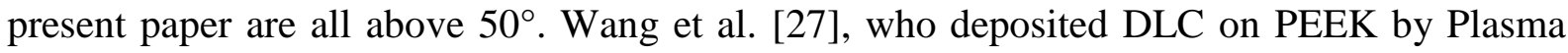
Immersion Ion Implantation and Deposition (PIII\&D) from a gas mixture of acetylene and argon, obtained a more hydrophilic coating as the water contact angle was $35^{\circ}$.

XPS results show that, even if no oxygen was introduced into the deposition chamber during the deposition of the hydrogenated amorphous carbon films, the a-C:H coatings do contain oxygen. This may be due to a degassing of water and oxygen by the PEEK polymer during the deposition process or to post-deposition chemical reactions between imprisoned radicals contained in the coatings and water and oxygen from ambient air. The content in $\mathrm{sp}^{2} \mathrm{C}=\mathrm{C}$ bond is assessed using two methods: deconvolution of the $\mathrm{C} 1 \mathrm{~s}$ peak and determination of the $\mathrm{D}$ parameter. The $\mathrm{C} 1 \mathrm{~s}$ peak deconvolution method results in a $\mathrm{sp}^{2} \mathrm{C}=\mathrm{C}$ bond content approximately twice higher than that obtained by the D parameter method. Other authors already reported this deviation between the two methods $[29,45]$. Nonetheless, both methods show the same trend: the a-C:H coating obtained with a bias voltage of $-100 \mathrm{~V}$ has a higher $\mathrm{sp}^{3}$ $\mathrm{C}-\mathrm{C}$ bond content than the polymer-like carbon coating without the silicon-doped DLC layer. Additionally, the $\mathrm{sp}^{3} / \mathrm{sp}^{2}$ ratios and $\mathrm{D}$ parameters obtained in the presented work are consistent with those obtained by Kaczorowski et al. [29], who also deposited DLC films on PEEK.

In terms of mechanical properties, the four hydrogenated amorphous carbon films that were deposited on PEEK have hardness values around 3GPa for the two polymer-like carbon coatings and around $5 \mathrm{GPa}$ when a bias voltage was applied during the process. The DLC film deposited on PEEK by PIII\&D by Wang et al. [27] has a hardness of $1.8 \mathrm{GPa}$ and an elastic modulus of $16 \mathrm{GPa}$. Both values are lower than what is obtained in our work, using a PECVD deposition technique. Kaczorowski et al. [28,29] studied the effect of different plasma etching treatments in methane, nitrogen or oxygen atmosphere before depositing a hydrogenated amorphous carbon film on PEEK from methane. The hydrogenated amorphous carbon films had a hardness between 1.6 and 2.5 GPa and a Young's modulus between 14 and $21 \mathrm{GPa}$. In 
the present work, all hydrogenated amorphous carbon films had a hardness of the same order of magnitude but slightly higher than that of other hydrogenated amorphous carbon films deposited on PEEK in the literature, except for the 300-nm thick DLC coatings deposited by Watanabe et al. [25]. They obtained coatings exhibiting hardness values between 12 and 26 GPa and Young's modulus values between 125 and $250 \mathrm{GPa}$, but very poor adhesion to the PEEK substrate in scratch testing (probably due to the large mismatch of mechanical behavior). For the four coatings presented in this paper, the ratio $\mathrm{H} / \mathrm{E}$, which is an indicator of wear resistance related to the elastic strain to failure, ranges from 0.13 to 0.15 , which is within the commonly accepted limits of DLC films $[15,46,47]$.

Without applying any bias voltage, the films have a high content in hydrogen, so that many $\mathrm{Csp}^{3}$ atoms are hydrogen-terminated causing the polymer-like carbon coatings to be very soft and supple [48]. The applied bias voltage cause the bombardment of the surface by high energy species being able to break up the $\mathrm{C}-\mathrm{H}$ bonds thus leading to a dehydrogenation of the films [49]. For the two a-C:H films obtained with biasing, there are less $\mathrm{Csp}^{3}$ atoms that are hydrogen-terminated and more $\mathrm{Csp}^{3}$ atoms are bonded to other carbon atoms (as suggested by the XPS analyses), thus causing the film to be harder and stiffer than with no bias voltage applied.

It is generally accepted that the compressive stress to which hydrogen-free DLC coatings is subject are created by the energetic particles bombarding the film surface during the deposition process (subplantation model) $[15,50,51]$. When a bias voltage is applied to the surface, positive ions in the plasma are accelerated to bombard the film surface and having acquired a higher kinetic energy, they cause an implantation of atoms below the surface creating local distortions in the film and leading to a higher final internal stress and an increased density in the films. For hydrogenated DLC coatings, the intensity of internal residual stress not only depends on the local distortions and density, but also on the total hydrogen content. More precisely, hydrogen atoms terminating $\mathrm{Csp}^{3}$ atoms in the network can 
release local distortions and thus compressive internal stress [50,52]. The two a-C:H films obtained with biasing showed higher compressive internal stress due to the bombardment of energetic particles leading to greater local distortions and less hydrogen-terminated $\mathrm{Csp}^{3}$ atoms hindering the release of compressive internal stress via hydrogen terminations in the network.

\subsection{Excellent adhesion as a key factor for a good tribological performance}

Good adhesion of the coating on the substrate is a key factor in many applications, and particularly, for articulating load bearing surfaces in biomedical applications. In this work, the two polymer-like carbon coatings with and without the Si-doped DLC underlayer have an excellent adhesion to the PEEK substrate as they showed a cohesive fracture in the PEEK in pull-off testing. On the other hand, the two a-C:H coatings obtained with biasing of the titanium underlayer show an adhesive fracture at the Ti/Si-doped DLC interface.

The adhesive fracture at the Ti/Si-doped DLC interface observed in pull-off testing may be due to a remaining titanium oxide layer. Indeed, a titanium oxide layer formed when the PECVD reactor was opened in order to make sure of a good electrical contact between the titanium surface and the substrate holder so that the bias voltage could be properly applied to the titanium layer. Maybe, the argon ion sputtering which was performed before the deposition of the Si-doped DLC layer was not sufficient to properly remove the titanium oxide layer.

For the two a-C:H films obtained with biasing, when the tribological testing was stopped at the very moment when the coating started to delaminate, it was observed that, in some areas, the hydrogenated amorphous carbon film was removed but not the titanium layer. Thus, the adhesion between the titanium and the Si-doped DLC layers may be partly responsible for the early delamination of these two types of coatings in tribological testing. Nonetheless, no 
delamination at the Ti/Si-doped DLC interface was observed in scratch testing, the delamination always occurred at the PEEK/titanium interface.

The presence of silicon in the first third of the coating does not seem to influence the adhesion on the PEEK substrate in the case of the polymer-like coatings in pull-off testing. Indeed, the polymer-like carbon coatings with and without the Si-doped DLC underlayer have a cohesive fracture in the PEEK substrate. However, the presence of silicon in the coating seems to be detrimental to the polymer-like carbon coating with the Si-doped DLC underlayer given that it tends to delaminate at the end of the tribological testing.

The slight delamination of the polymer-like carbon film with the Si-doped DLC underlayer at the end of the tribological testing may be due to a hydrolysis of the Si-O bonds at the PEEK/Si-doped DLC interface. Indeed, the oxygen plasma treatment performed before the deposition of the Si-doped DLC aimed at grafting oxygen at the PEEK surface and creating $\mathrm{C}-\mathrm{O}$ or $\mathrm{Si}-\mathrm{O}$ covalent bonds at the interface. Being immersed in an aqueous environment for several hours, the PEEK/Si-doped DLC interface may have undergone a hydrolysis of the SiO bonds, thus weakening the interface and leading to a slight delamination at the end of the tribological testing. Proteins might also be responsible for an enhancement of the hydrolysis of silicon-oxygen bonds [23].

The higher residual internal stress of the two a-C:H obtained with biasing of the titanium layer may also contribute to their lower adhesion as the adhesion strength was found to be inversely proportional to the residual internal stress of the coating [53].

It is also to be noted that the tribological testing in terms of deformation of the substrate was rather severe. Indeed, for a PEEK-on-alumina contact, the maximum indentation depth related to the $20 \mathrm{~N}$ normal force was $9.5 \mu \mathrm{m}$ which was much larger than the thickness of the coatings. 
Kaczorowski et al. [28,29] tested DLC-coated PEEK surfaces in terms of tribological performance. They tested hydrogenated amorphous carbon coatings deposited on PEEK against a zirconia ball on rotative ball-on-disc tribometer in dry conditions. The mean Hertzian contact pressure was $82 \mathrm{MPa}$ (the normal force was $5 \mathrm{~N}$ and the diameter of the zirconia ball was $6.35 \mathrm{~mm}$ ) which means that the maximum contact pressure was higher than the plastic yield stress of PEEK, and also higher than in the present work. The specific wear rate of PEEK they obtained was very low compared with the one which is obtained in the present work $\left(9.7 \times 10^{-5} \mathrm{~mm}^{3} \mathrm{~N}^{-1} \mathrm{~m}^{-1}\right)$. The specific wear of the hydrogenated carbon coatings elaborated by Kaczorowski et al. by hybrid microwave/radiofrequency PECVD was 2-2.3 $\times$ $10^{-7} \mathrm{~mm}^{3} \mathrm{~N}^{-1} \mathrm{~m}^{-1}$. The coatings elaborated by conventional radiofrequency PECVD had a lower specific wear rate of $0.3-2 \times 10^{-8} \mathrm{~mm}^{3} \mathrm{~N}^{-1} \mathrm{~m}^{-1}$. In the present work, the polymer-like carbon coating without the Si-doped DLC underlayer exhibiting an excellent adhesion to the PEEK substrate, has a specific wear rate of $1.1 \times 10^{-8} \mathrm{~mm}^{3} \mathrm{~N}^{-1} \mathrm{~m}^{-1}$ which is comparable to those obtained by Kaczorowski et al. (even though the tribological conditions were significantly different). In terms of friction, Kaczorowski et al. [29] also observed a smoother evolution of the coefficient of friction once DLC was deposited on PEEK compared with the uncoated PEEK. In dry conditions, the coefficient of friction of the uncoated PEEK was about 0.4, which was slightly larger than what we observed in bovine calf serum conditions. As for DLC-coated PEEK, the coefficient of friction was between 0.25 and 0.3 at the end of the test, depending on the plasma etching treatment. In our work, the coefficient of friction of the two polymer-like carbon coatings was about 0.23 at the end of the test in bovine calf serum conditions.

In the literature, two other authors investigated the tribological behavior of DLC-coated PEEK surfaces. Tomaszewski et al. [26] deposited 600-nm thick DLC coatings on natural and carbon-fiber reinforced PEEK by PECVD. They showed that, after coating deposition, the coefficient of friction was reduced from $0.26-0.31$ to $0.09-0.13$ and that the coatings were 
stable and exhibited no measurable wear when rubbed against Ti6Al4V balls in dry conditions. Watanabe et al. [25], who deposited very hard and stiff DLC coatings on PEEK, observed an increase in the coefficient of friction after film deposition when rubbing against a polyamide ball in dry conditions. In addition, they observed cracks and delaminations of the coatings in tiribological testing due to the large film/substrate mismatch of mechanical behavior.

Given that in tribological testing it is interesting to examine both rubbing bodies, the alumina counterbody was examined. No wear could be measured on the alumina ball for all tribological couples tested. No tribofilm is formed on the alumina ball when it was rubbed against the two polymer-like carbon coatings. The absence of tribofilm formation on the alumina is assumed to be due to the proteins contained in the bovine calf serum solution. Indeed, proteins, in particular albumins and globulins, tend to adsorb on articulating surfaces, in our case on the coating and the alumina ball, and prevent the formation of a transfer layer on the alumina ball [32]. 


\section{CONCLUSIONS}

The four a-C:H films deposited on PEEK were characterized physico-chemically, mechanically and tribologically. After film deposition there was an increase in surface roughness and surface free energy compared with the uncoated PEEK surface.

Two distinct behaviors could be pointed out in terms of mechanical and tribological properties. The two polymer-like carbon coatings showed low hardness and Young's modulus compared with what is generally achieved for diamond-like carbon films [15]. They also showed very low internal stress. The very good adhesion of the two polymer-like carbon coatings to the PEEK proven by the cohesive fracture in the PEEK was achieved through an oxygen plasma treatment before film deposition. The two polymer-like carbon coatings also performed well in scratch testing since the coatings were still partially adhering to the substrate at a normal load of $10 \mathrm{~N}$ and did not delaminate in a large-flake way. In tribological testing, the two polymer-like carbon coatings enabled a reduction of the coefficient of friction near 0.1 and a decrease in wear compared with the uncoated PEEK substrate. The polymerlike carbon coating without the silicon-doped DLC underlayer enabled an almost 10000-fold decrease in wear and barely showed signs of wear whereas the polymer-like carbon coating with the silicon-doped DLC underlayer only showed a 600-fold decrease in wear. The lower decrease in wear of the polymer-like carbon coating with the silicon-doped DLC underlayer was due to the slight and localized delamination of coating at the end of the tribological testing which was possibly caused by a hydrolysis of the Si-O bonds in bovine calf serum conditions.

The two a-C:H coatings obtained with biasing of the titanium underlayer showed higher hardness, Young's modulus and residual compressive internal stress than the two polymerlike carbon coatings. The bombardment of energetic species onto the surface caused, on one 
side, a dehydrogenation of the coating and an increase in $\mathrm{C}-\mathrm{C}$ bonds explaining the increases in hardness and Young's modulus and, on the other side, the implantation of atoms below the surface being responsible for the increase in compressive internal stress. However, the two hydrogenated amorphous carbon coatings obtained with biasing were subject to an adhesive fracture at the titanium/silicon-doped DLC interface and a spallation failure mode, which means that they had a weaker adhesion than what was achieved for the two polymer-like carbon coatings. The two hydrogenated amorphous carbon coatings also suffered from an early delamination during tribological testing after only a few hundreds or thousands of cycles. The early delamination and the adhesive fracture at the titanium/silicon-doped DLC interface were assumed to be due to a remaining titanium oxide layer which was not properly removed by argon sputtering after the opening of the PECVD reactor and to the higher residual internal stress of the two a-C:H coatings obtained with biasing.

The most suitable coating for a biomedical application would be the polymer-like carbon coating without the silicon-doped DLC underlayer as it enabled a reduction of wear, had a very good adhesion to the PEEK substrate and, most importantly, was never subject to delamination in tribological testing.

\section{ACKNOWLEDGEMENTS}

This work was supported by the LABEX MANUTECH-SISE (ANR-10-LABX-0075) of Université de Lyon, within the program "Investissements d'Avenir" (ANR-11-IDEX-0007) operated by the French National Research Agency (ANR). 


\section{REFERENCES}

[1] H. Koike, K. Kida, E.C. Santos, J. Rozwadowska, Y. Kashima, K. Kanemasu, Selflubrication of PEEK polymer bearings in rolling contact fatigue under radial loads, Tribol. Int. 49 (2012) 30-38. doi:10.1016/j.triboint.2011.12.005.

[2] A. Murari, A. Barzon, Comparison of new PEEK seals with traditional helicoflex for ultra high vacuum applications, User Model. User-Adapt. Interact. 72 (2003) 327-334. doi:10.1016/j.vacuum.2003.08.011.

[3] J.M. Toth, Biocompatibility of Polyaryletheretherketone Polymers, in: PEEK Biomater. Handb., Elsevier Inc., 2012: pp. 81-92. doi:10.1016/B978-1-4377-44637.10007-7.

[4] S. Najeeb, M.S. Zafar, Z. Khurshid, F. Siddiqui, Applications of polyetheretherketone (PEEK) in oral implantology and prosthodontics, J. Prosthodont. Res. 60 (2016) 12-19. doi:10.1016/j.jpor.2015.10.001.

[5] H. Xin, D.E.T. Shepherd, K.D. Dearn, A tribological assessment of a PEEK based selfmating total cervical disc replacement, Wear. 303 (2013) 473-479.

doi:10.1016/j.wear.2013.03.052.

[6] T.M. Grupp, H.J. Meisel, J.A. Cotton, J. Schwiesau, B. Fritz, W. Blömer, V. Jansson, Alternative bearing materials for intervertebral disc arthroplasty, Biomaterials. 31 (2010) 523-531. doi:10.1016/j.biomaterials.2009.09.064.

[7] T. Schwenke, T. Brown, Q. Bao, T. Kilpela, M. Wimmer, Wear Assessment of a SelfMating Polymer for Nucleus Replacement Devices, in: 53rd Annu. Meet. Orthop. Res. Soc. Poster No 1125, 2004.

[8] M. Kraft, D.K. Koch, M. Bushelow, An investigation into PEEK-on-PEEK as a bearing surface candidate for cervical total disc replacement, Spine J. 12 (2012) 603611. doi:10.1016/j.spinee.2012.07.009.

[9] S. Bauer, P. Schmuki, K. von der Mark, J. Park, Engineering biocompatible implant surfaces. Part I: Materials and surfaces, Prog. Mater. Sci. 58 (2012) 261-326. doi:10.1016/j.pmatsci.2012.09.001.

[10] P.K. Chu, Surface engineering and modification of biomaterials, Thin Solid Films. 528 (2013) 93-105. doi:10.1016/j.tsf.2012.07.144. 
[11] F. Awaja, S. Zhang, N. James, D.R. McKenzie, Enhanced Autohesive Bonding of Polyetheretherketone (PEEK) for biomedical applications using a methane/oxygen plasma treatment, Plasma Process. Polym. 7 (2010) 1010-1021. doi:10.1002/ppap.201000072.

[12] A.H.C. Poulsson, R.G. Richards, Surface Modification Techniques of Polyetheretherketone, Including Plasma Surface Treatment, in: PEEK Biomater. Handb., Elsevier Inc., 2012: pp. 145-161. doi:10.1016/B978-1-4377-4463-7.10010-7.

[13] S. Hammouti, A. Pascale-Hamri, N. Faure, B. Beaugiraud, M. Guibert, C. Mauclair, S. Benayoun, S. Valette, Wear rate control of peek surfaces modified by femtosecond laser, Appl. Surf. Sci. 357 (2015) 1541-1551. doi:10.1016/j.apsusc.2015.09.204.

[14] C. Donnet, A. Erdemir, Tribology of Diamond-Like Carbon Films: Fundamentals and Applications, 2008. doi:10.1017/CBO9781107415324.004.

[15] J. Robertson, Diamond-like amorphous carbon, Mater. Sci. Eng. R Reports. 37 (2002) 129-281. doi:10.1016/S0927-796X(02)00005-0.

[16] M. Santos, M.M.M. Bilek, S.G. Wise, Plasma-synthesised carbon-based coatings for cardiovascular applications, Biosurface and Biotribology. 1 (2015) 146-160. doi:10.1016/j.bsbt.2015.08.001.

[17] G. Thorwarth, C. V. Falub, U. Müller, B. Weisse, C. Voisard, M. Tobler, R. Hauert, Tribological behavior of DLC-coated articulating joint implants, Acta Biomater. 6 (2010) 2335-2341. doi:10.1016/j.actbio.2009.12.019.

[18] R. Lappalainen, M. Selenius, A. Anttila, Y.T. Konttinen, S.S. Santavirta, Reduction of wear in total hip replacement prostheses by amorphous diamond coatings., J. Biomed. Mater. Res. B. Appl. Biomater. 66 (2003) 410-413. doi:10.1002/jbm.b.10026.

[19] V. Tiainen, Amorphous carbon as a bio-mechanical coating - mechanical properties and biological applications, Diam. Relat. Mater. 10 (2001) 153-160. doi:10.1016/S0925-9635(00)00462-3.

[20] A. Anttila, J. Salo, R. Lappalainen, High adhesion of diamond-like films achieved by the pulsed arc-discharge method, Mater. Lett. 24 (1995) 153-156. doi:10.1016/0167577X(95)00071-2. 
[21] T.J. Joyce, Examination of failed ex vivo metal-on-metal metatarsophalangeal prosthesis and comparison with theoretically determined lubrication regimes, Wear. 263 (2007) 1050-1054. doi:10.1016/j.wear.2006.11.045.

[22] R. Hauert, K. Thorwarth, G. Thorwarth, An overview on diamond-like carbon coatings in medical applications, Surf. Coatings Technol. 233 (2013) 119-130.

doi:10.1016/j.surfcoat.2013.04.015.

[23] L. Chandra, M. Allen, R. Butter, N. Rushton, A.H. Lettington, T.W. Clyne, The Effect of Exposure to Biological-Fluids on the Spallation Resistance of Diamond-Like Carbon Coatings on Metallic Substrates, J. Mater. Sci. Med. 6 (1995) 581-589. doi:10.1007/BF00121282.

[24] R. Hauert, C. V. Falub, G. Thorwarth, K. Thorwarth, C. Affolter, M. Stiefel, L.E. Podleska, G. Taeger, Retrospective lifetime estimation of failed and explanted diamond-like carbon coated hip joint balls, Acta Biomater. 8 (2012) 3170-3176. doi:10.1016/j.actbio.2012.04.016.

[25] Y. Watanabe, H. Suzuki, M. Nakamura, Improvement of the tribological property by DLC coating for environmentally sound high polymer materials, Int. J. Mater. Prod. Technol. 2 (2001) 787-792.

[26] P.K. Tomaszewski, Y.T. Pei, G.J. Verkerke, J. De Hosson, Improved tribological performance of PEEK polymers by application of diamond-like carbon coatings, Eur. Cells Mater. 27 (2014) 4.

[27] H. Wang, M. Xu, W. Zhang, D.T.K. Kwok, J. Jiang, Z. Wu, P.K. Chu, Mechanical and biological characteristics of diamond-like carbon coated poly aryl-ether-ether-ketone, Biomaterials. 31 (2010) 8181-8187. doi:10.1016/j.biomaterials.2010.07.054.

[28] W. Kaczorowski, W. Szymanski, D. Batory, P. Niedzielski, Tribological properties and characterization of diamond like carbon coatings deposited by MW/RF and RF plasmaenhanced CVD method on poly(ether-ether-ketone), Steel Res. Int. 11 (2014) 878-887. doi:10.1002/ppap.201400025.

[29] W. Kaczorowski, D. Batory, W. Szymanski, P. Niedzielski, Evaluation of the surface properties of PEEK substrate after two-step plasma modification: Etching and deposition of DLC coatings, Surf. Coatings Technol. 265 (2015) 92-98. doi:10.1016/j.surfcoat.2015.01.053.

[30] S. Zhang, F. Awaja, N. James, D.R. McKenzie, A.J. Ruys, Autohesion of plasma 
treated semi-crystalline PEEK: Comparative study of argon, nitrogen and oxygen treatments, Colloids Surfaces A Physicochem. Eng. Asp. 374 (2011) 88-95. doi:10.1016/j.colsurfa.2010.11.013.

[31] R. Matsumoto, K. Sato, K. Ozeki, K. Hirakuri, Y. Fukui, Cytotoxicity and tribological property of DLC films deposited on polymeric materials, Diam. Relat. Mater. 17 (2008) 1680-1684. doi:10.1016/j.diamond.2008.02.027.

[32] R. Hauert, DLC Films in Biomedical Applications, in: Tribol. Diamond-Like Carbon Film. Fundam. Appl., 2008: pp. 494-509. doi:10.1007/978-0-387-49891-1_20.

[33] X.M. Chen, Z.M. Jin, J. Fisher, Effect of albumin adsorption on friction between artificial joint materials, Proc. Inst. Mech. Eng. Part J-Journal Eng. Tribol. 222 (2008) 513-521. doi:10.1243/13506501JET371.

[34] A.P. Carapeto, A.P. Serro, B.M.F. Nunes, M.C.L. Martins, S. Todorovic, M.T. Duarte, V. André, R. Colaço, B. Saramago, Characterization of two DLC coatings for joint prosthesis: The role of albumin on the tribological behavior, Surf. Coatings Technol. 204 (2010) 3451-3458. doi:10.1016/j.surfcoat.2010.04.022.

[35] M. Kalin, M. Polajnar, The wetting of steel, DLC coatings, ceramics and polymers with oils and water: The importance and correlations of surface energy, surface tension, contact angle and spreading, Appl. Surf. Sci. 293 (2014) 97-108.

doi:10.1016/j.apsusc.2013.12.109.

[36] S. Yamamoto, A. Kawana, C. Masuda, Tribological behavior of diamond-like carbon produced by rf-PCVD based on energetic evaluation, Surf. Coatings Technol. 236 (2013) 457-464. doi:10.1016/j.surfcoat.2013.10.037.

[37] J.C. Lascovich, R. Giorgi, S. Scaglione, Evaluation of the sp2/sp3 ratio in amorphous carbon structure by XPS and XAES, Appl. Surf. Sci. 47 (1991) 17-21. doi:10.1016/0169-4332(91)90098-5.

[38] A. Mezzi, S. Kaciulis, Surface investigation of carbon films: From diamond to graphite, Surf. Interface Anal. 42 (2010) 1082-1084. doi:10.1002/sia.3348.

[39] G.G. Stoney, The Tension of Metallic Films deposited by Electrolysis, Proc. R. Soc. London A Math. Phys. Eng. Sci. 82 (1909) 172-175. doi:10.1098/rspa.1909.0021.

[40] A. Mézin, Coating internal stress measurement through the curvature method: A 
geometry-based criterion delimiting the relevance of Stoney's formula, Surf. Coatings Technol. 200 (2006) 5259-5267. doi:10.1016/j.surfcoat.2005.06.018.

[41] W.C. Oliver, G.M. Pharr, Measurement of hardness and elastic modulus by instrumented indentation: Advances in understanding and refinements to methodology, J. Mater. Res. 19 (2004) 3-20. doi:10.1557/jmr.2004.19.1.3.

[42] P.J. Burnett, D.S. Rickerby, The relationship between hardness and scratch adhession, Thin Solid Films. 154 (1987) 403-416. doi:10.1016/0040-6090(87)90382-8.

[43] K.N. Pandiyaraj, V. Selvarajan, J. Heeg, F. Junge, A. Lampka, T. Barfels, M. Wienecke, Y.H. Rhee, H.W. Kim, Influence of bias voltage on diamond like carbon (DLC) film deposited on polyethylene terephthalate (PET) film surfaces using PECVD and its blood compatibility, Diam. Relat. Mater. 19 (2010) 1085-1092. doi:10.1016/j.diamond.2010.03.016.

[44] M. Grischke, K. Bewilogua, K. Trojan, H. Dimigen, Application-oriented modifications of deposition processes for diamond-like-carbon-based coatings, Surf. Coatings Technol. 74-75 (1995) 739-745. doi:10.1016/0257-8972(94)08201-4.

[45] B.J. Jones, J.J. Ojeda, Substrate and material transfer effects on the surface chemistry and texture of diamond-like carbon deposited by plasma enhanced CVD, Surf. Interface Anal. 44 (2012) 1187-1192. doi:http://dx.doi.org/10.1002/sia.4871.

[46] J. Fontaine, C. Donnet, A. Erdemir, Fundamentals of the tribology of DLC coatings, in: Tribol. Diamond-Like Carbon Film. Fundam. Appl., 2008: pp. 139-154. doi:10.1007/978-0-387-49891-1_5.

[47] A. Leyland, A. Matthews, On the significance of the H/E ratio in wear control: A nanocomposite coating approach to optimised tribological behaviour, Wear. 246 (2000) 1-11. doi:10.1016/S0043-1648(00)00488-9.

[48] P. Lemoine, J.P. Quinn, P.D. Maguire, J.A. Mclaughlin, Mechanical Characterisation and Properties of DLC Films, in: Tribol. Diamond-Like Carbon Film. Fundam. Appl., 2008: pp. 83-101. doi:10.1007/978-0-387-49891-1_3.

[49] W. Tillmann, F. Hoffmann, S. Momeni, R. Heller, Hydrogen quantification of magnetron sputtered hydrogenated amorphous carbon $(\mathrm{a}-\mathrm{C}: \mathrm{H})$ coatings produced at various bias voltages and their tribological behavior under different humidity levels, Surf. Coatings Technol. 206 (2011) 1705-1710. doi:10.1016/j.surfcoat.2011.07.089. 
[50] Y. Pauleau, Residual stresses in DLC films and adhesion to various substrates, in: Tribol. Diamond-Like Carbon Film. Fundam. Appl., 2008: pp. 102-136. doi:10.1007/978-0-387-49891-1_4.

[51] C.A. Davis, A simple model for the formation of compressive stress in thin films by ion bombardment, Thin Solid Films. 226 (1993) 30-34. doi:10.1016/00406090(93)90201-Y.

[52] M. Ban, T. Hasegawa, S. Fujii, J. Fujioka, Stress and structural properties of diamondlike carbon films deposited by electron beam excited plasma CVD, Diam. Relat. Mater. 12 (2003) 47-56. doi:10.1016/S0925-9635(02)00265-0.

[53] M.M. Morshed, B.P. McNamara, D.C. Cameron, M.S.J. Hashmi, Stress and adhesion in DLC coatings on 316L stainless steel deposited by a neutral beam source, J. Mater. Process. Technol. 143-144 (2003) 922-926. doi:10.1016/j.jmatprotec.2003.10.003. 